The submitted manubcript has ben authored by a contractor of the United States Government under contraot. Accordingly the United States Gorp. ernment retains a non-exclusiva, royalty-free license to publish or reproduce the publighed form of this contribution, or allow others to do so, for United States Government pur. powar.

\title{
DEFORMATION MICROSTRUCTURES AND SELECTED EXAMPLES OF THEIR RECRYSTALLIZATION ${ }^{*}$
}

\author{
D. A. Hughes \\ Center for Materials and Engineering Sciences \\ Sandia National Laboratories, Livermore, CA 94551-0969 USA
}

\begin{abstract}
The elements that are needed to describe a deformation structure: grains, grain boundaries, macro-scale banding within crystals, cell blocks, geometrically necessary boundaries and incidental dislocation boundaries (cell boundaries) are presented and described for fcc metals and alloys of medium to high stacking fault energy. Pertinent to this quantitative description are the local orientations, structural morphology, different boundary misorientations and spacings as a function of strain and deformation conditions. Three specific examples are given in which particular aspects of the deformation structure are shown to direct the recrystallization behavior.
\end{abstract}

\section{INTRODUCTION}

The words deformation microstructure may conjure up both different visual pictures and nomenclature depending on one's background or familiar points of reference. This disparity can range from martensite formation in TRIP steels to nearly perfect low angle subgrains in high temperature creep. Even when the frame of reference is narrowed to monotonic cold deformation structures in single phase fcc metals and alloys, as in this paper, disparities can be found. For example it may be easiest to describe deformation structures as a simple cell structure to those outside the field. The early work on polycrystals and the beautiful examples from tensile deformed [100] oriented copper single crystals (e.g., (Swann 1963; Gottler 1973; Mughrabi, Ungar, Kienle and Wilkens 1986)) has strongly influenced a collective bias towards this simple view. However to form a strong basis that links the developing microstructure to the changing properties, this oversimplified picture must be replaced with one that includes the broader range of observed features. These different features may play different roles in the nucleation and growth of recrystallization as well as in the development of other properties, like mechanical, that are less central to the present symposium.

\footnotetext{
"This paper is dedicated to Niels Hansen whose next career phase is expected to acheive the scientific excellence, inspiration and foresight that have distinguished his tenure at Risø.
} 


\section{DISCLAIMER}

This report was prepared as an account of work sponsored by an agency of the United States Government. Neither the United States Government nor any agency thereof, nor any of their employees, make any warranty, express or implied, or assumes any legal liability or responsibility for the accuracy, completeness, or usefulness of any information, apparatus, product, or process disclosed, or represents that its use would not infringe privately owned rights. Reference herein to any specific commercial product, process, or service by trade name, trademark, manufacturer, or otherwise does not necessarily constitute or imply its endorsement, recommendation, or favoring by the United States Government or any agency thereof. The views and opinions of authors expressed herein do not necessarily state or reflect those of the United States Government or any agency thereof. 


\section{DISCLAIMER}

Portions of this document may be illegible in electronic image products. Images are produced from the best available original document. 
a)

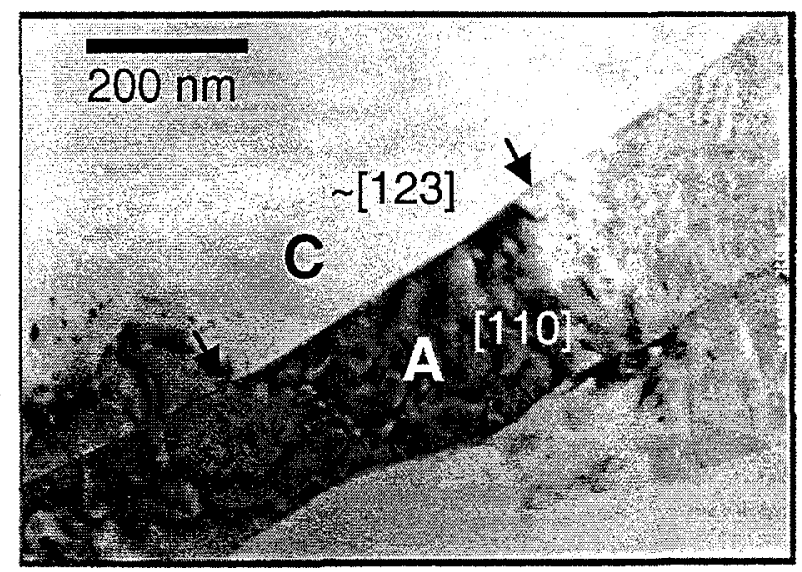

b)

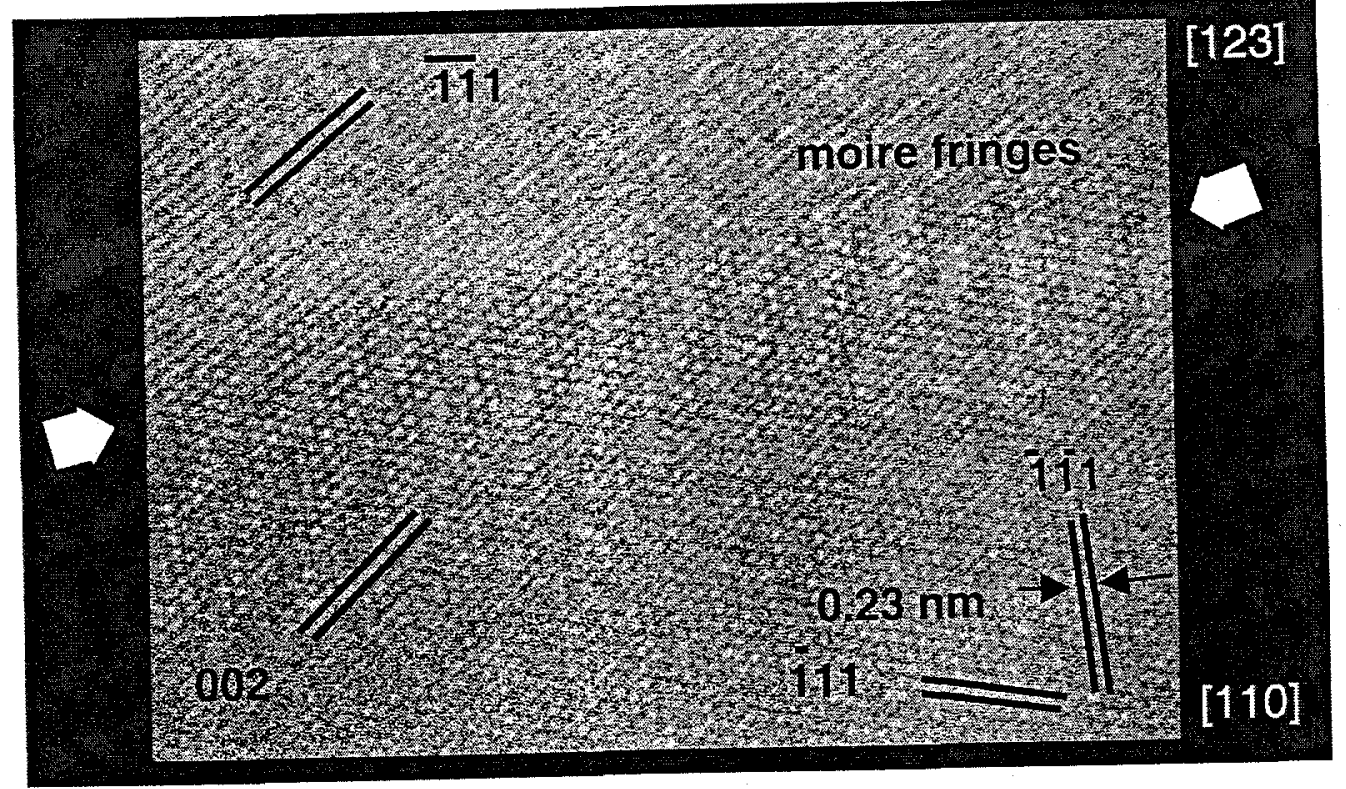

Fig. 1. Transmission electron micrographs of a deformation induced high angle boundary in commercial purity aluminum, cold rolled $90 \%, \varepsilon_{\mathrm{vM}}=2.7$. (a) High angle boundary between band $\mathrm{A}$ and $\mathrm{C}$ with foil normals of [110] and $\sim$ [123] respectively. The boundary misorientation angle/axis pair is $26.5^{\circ}$ [401]. (b) High resolution TEM showing a fairly narrow deformation induced boundary with little distortion of the lattice planes as they approach the boundary. No lattice dislocations were observed in the vicinity of the boundary. The boundary location is indicated by arrows. Note that the boundary is slightly inclined to the electron beam as indicated by the Moire fringes. The spacing of the resulting Moiré fringe corresponds to the angle between $\{-1-11\}$ in $\mathrm{C}$ and $\{002\}$ in $\mathrm{A}$ (Medlin and Hughes 2000).

In the following, the context of grain subdivision is used to create a more complete description of deformation microstructures. Then specific examples are selected to illustrate how these structures influence recrystallization, nucleation and growth.

\section{GRAIN SUBDIVISION AND DEFORMATION MICROSTRUCTURES}

2.1. Grains and grain boundaries. As an elementary starting point, first consider fully recrystallized fcc polycrystals of medium to high stacking fault energy (SFE). Prior to the start of deformation, the grain size and crystal orientation distribution of the grains are the main 


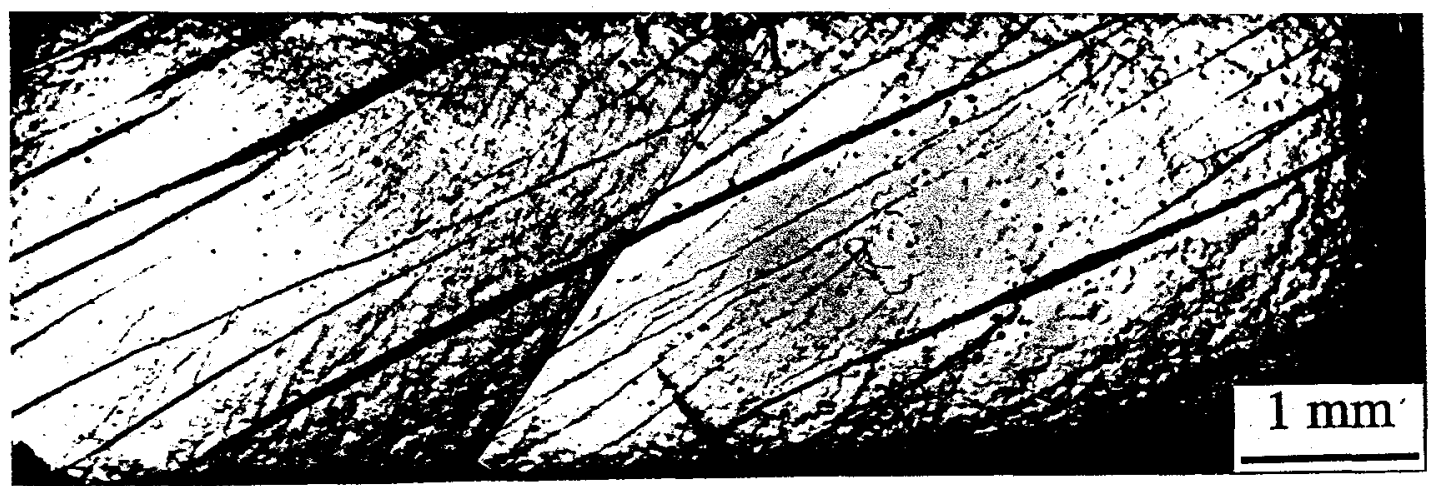

Fig. 2. Macro-scale bands formed in an aluminum single crystal compressed along the [421] direction to a strain of $\varepsilon_{\mathrm{yM}}=0.37$. Polarized light micrograph with the compression axis running vertically in the photo.

features. The grains, delineated by grain boundaries may be equiaxed, cigar or pancake shaped. The grain interiors are nearly perfect crystals containing only a few fairly isolated dislocations. As deformation proceeds the interior of a grain is filled by a dislocation structure. While this structure will exhibit certain general characteristics to be defined in the next section, specific aspects of this structure will depend systematically on the grain orientation (Huang and Hansen 1997). On occasion the relationship between the two or three adjacent grains and their mutual boundary, may create conditions that alter the dislocation structure immediately adjacent to the grain boundary or grain boundary triple point, i.e. within $\sim 1-5 \mu \mathrm{m}$, e.g., (Fujita, Toyoda, Mori, Tabata, Ono and Takeda 1983; Hansen 1985; Barlow, Bay and Hansen 1985).

The location of the original grain boundaries remains clear at small to medium strain, $0<\varepsilon_{\mathrm{yM}}<1$, albeit with a geometric shape change of the grains imposed by the deformation and with changes to the boundaries induced by crystal rotations in the grain interiors. However distinguishing their location within the overall structure becomes ever more difficult with increasing strain, until at strain $\varepsilon_{\mathrm{vM}}>3$, very few, if any, original grains and grain boundaries can be identified. Indeed "original" grain boundaries becomes a misnomer considering the large number of dislocations that have been absorbed by the boundaries and the large crystal rotations that have taken place on either side. Rather, the microstructure contains a fine distribution of extended deformation induced high angle $\left(>15^{\circ}\right)$ boundaries. Only about $1 / 4$ of these new high angle boundaries may have original grain boundaries as their source. The larger fraction is created by the deformation process. These new extended high angle boundaries approach many of the attributes associated with equilibrium grain boundaries including narrow widths and organized internal structure as evidenced by the high resolution electron micrograph (Fig. 1a and b) (Medlin and Hughes 2000); see also (Ganapathi, Aindow, Fraser and Rigney 1991).

2.2. Macro-scale layered structures. For very coarse, roughly $>500 \mu \mathrm{m}$, diameter grains, multicrystals, bicrystals or single crystals, it has been repeatably observed from the time of Barrett and Levenson (1940), e.g., see, also (Wonsiewicz and Chin 1970; Malin, Huber and Hatherly 1981; Akef and Driver 1991; Becker, Butler, Hu and Lalli 1991; Liu and Hansen 1998), that a number of "crystals" develop large scale layers or bands during deformation which may be observed optically (Fig. 2). The scale of these bands may be from tens of micrometers to millimeters in length and micrometers to 100 micrometers wide. These bands have been variously named deformation bands, transition bands, matrix bands, bands of secondary slip and kink bands (Barrett and Levenson 1940; Cahn 1951; Honeycombe 1951; Calnan 1952; Dillamore and Katoh 1974; Malin et al. 1981; Akef and Driver 1991; Becker et al. 1991; Liu and Hansen 1998). This range of names reflects in part the nature or origin of the bands. For 


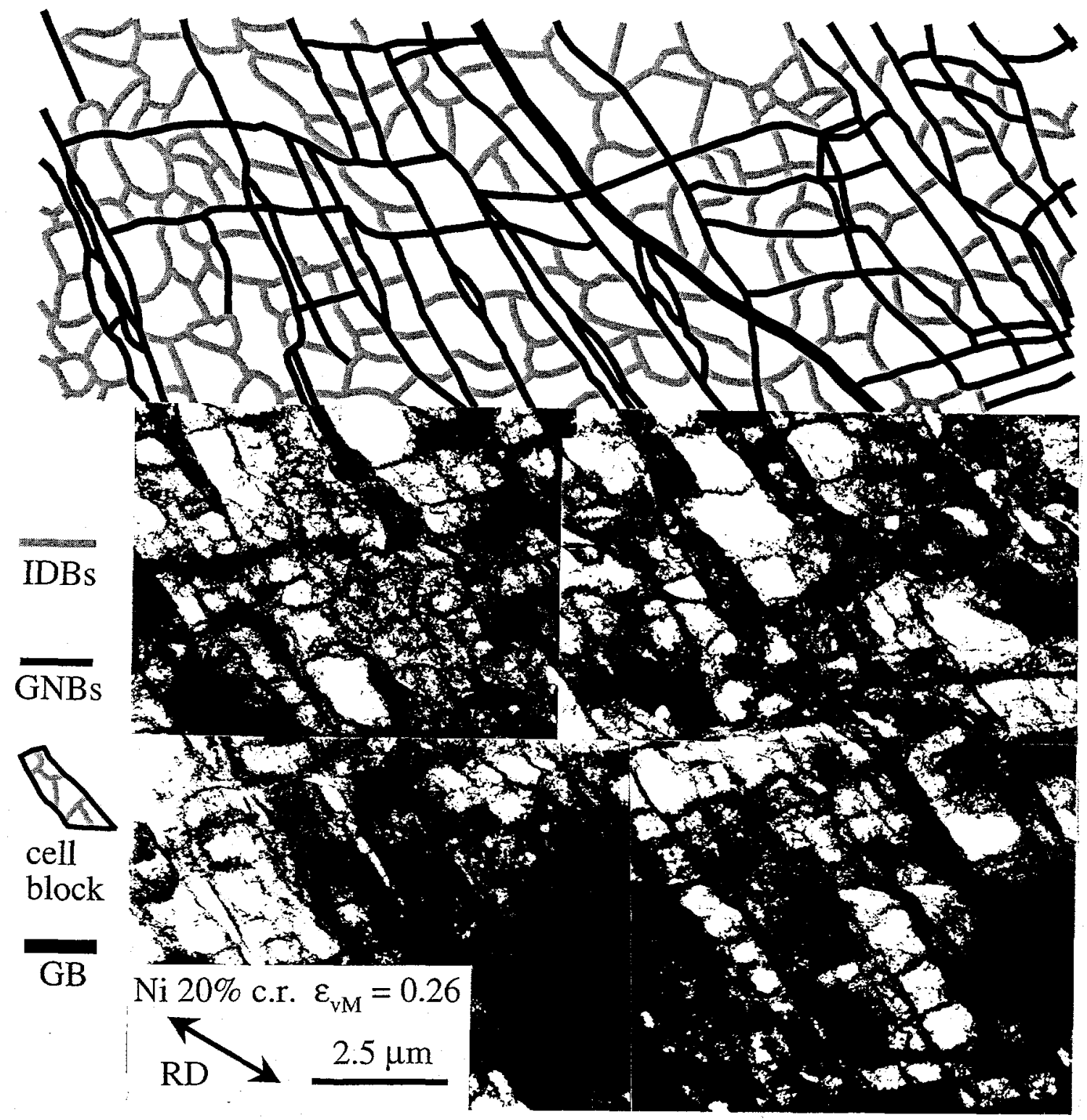

Fig. 3. TEM micrograph illustrating the cell block dislocation microstructure observed in pure nickel following a $20 \%$ reduction by cold rolling (cr) (equivalent von Mises strain, $\varepsilon_{\mathrm{vM}}=0.26$ ). At the top of figure is a tracing of the underlying and adjacent micrograph to show the cell block structure composed of IDBs and GNBs. Long GNBs (i.e., DDWs/MBs) are parallel to the main $\{111\}$ slip planes and inclined to the rolling direction (marked RD). Sections of two grains are visible with a grain boundary running diagonally. Viewing plane is the longitudinal section containing the normal and rolling directions.

example, transition bands applies to the more specific case of a gradient in orientation across the band. The cause of this banding has been related to modifications of the slip systems due to the depth and pattern of friction forces, e.g. at the roll-sample-interface in rolling or in channel die, e.g., (Wonsiewicz and Chin 1970; Lee, Duggan and Smallman 1993; Wert, Liu and Hansen 1997; Liu and Hansen 1998), as well as to the accommodation of grip ends in tension ( e.g., kink bands (Cahn 1951; Honeycombe 1951; Calnan 1952)) or the platens in compression (Hughes and Godfrey 1998). In all cases what makes these bands distinguishable optically is not a sharp pair of boundaries defining the edges, but rather the differences in local orientation as well as differences in the morphology of the dislocation structures within them. Indeed if one zooms in on a band one finds a basic cell block structure whose local orientations and boundary 
morphology delineate the bands. Note that a cell block structure is the basic structure of grains or crystals that do not exhibit macro-scale bands.

2.3. Cell blocks. Dislocations that are trapped within the grains during deformation form more or less two dimensional boundaries with dislocation poor regions between the boundaries. When a grain sized area is surveyed in the transmission electron microscope (TEM) it is observed that the average deformed grain contains sets of nearly parallel extended planar boundaries. A few of these may span nearly the whole grain. Sandwiched between these extended boundaries are groups of equiaxed cells. Together the two structures form a cell block (Bay, Hansen and Kuhlmann-Wilsdorf 1989; Bay, Hansen, Hughes and Kuhlmann-Wilsdorf 1992) (Fig. 3). The cell block structure is observed to persist from small to large strains with an evolution in the morphology of the cell block and the parameters that quantitatively describe it, e.g., how many cells wide, deep and long; spacing; boundary misorientation angle, boundary plane, e.g., (Hughes and Hansen 2000).

At small strains these extended boundaries are called dense dislocation walls (DDWs), if single and microbands (MBs), if in closely spaced pairs or strings of fine cells (Bay et al. 1992). They form with preferred planar orientations related to the crystal slip including near the main slip plane or deviated away from that plane about special rotation axes (Malin and Hatherly 1979; Bay et al. 1992; Winther, Huang and Hansen 2000). Second parallel sets may form on planes related to other highly activated slip planes. These preferred planes depend on grain orientation (Huang and Hansen 1997; Winther et al. 2000). This relation to the slip systems, results in a spread of boundary inclination angles that may also have a macroscopic relation to the sample, e.g., (Christoffersen and Leffers 1998). From medium to large strain there is a transition in the inclination angles observed. Thus at large strain these boundaries are nearly parallel to the extension direction, e.g. the rolling plane in rolling (Fig. 4). The closely spaced extended boundaries are called lamellar boundaries (LB) due to their resemblance to a tablet of sheets. The name change also reflects the transition in inclination angles and the change in the morphology of the cell block they define (Hughes and Hansen 2000).

2.4. Geometrically necessary boundaries. Together the DDWs, MBs, LBs which enclose and delineate cell blocks constitute a general class of boundary called a geometrically necessary boundary (GNB) (Kuhlmann-Wilsdorf and Hansen 1991). This classification is based on the hypothesis that the angular rotations of GNBs is controlled by disparity of glide induced lattice rotations that arise form different combinations of slip systems. This character results in a very strong increase in the rotation angle of GNBs, $\theta_{\mathrm{av}}{ }^{\mathrm{GNB}}$, with increasing strain (Fig. 5) and the formation of deformation induced high angle boundaries at large strain (Fig. 6). The spacing, $\mathrm{D}_{\mathrm{av}}{ }^{\mathrm{GNB}}$, between these boundaries decreases monotonically with increasing strain as shown in Fig. 5. No saturation in angle increase or spacing decrease is observed with increasing strain.

2.5. Incidental dislocation boundaries. The cell walls belong to a class of boundaries called incidental boundaries (IDBs) (Kuhlmann-Wilsdorf and Hansen 1991). These boundaries are hypothesized to form by statistical trapping of dislocations (Kublmann-Wilsdorf and Hansen 1991; Pantleon 1998). While these boundaries separate slightly rotated volumes, the misorientation angle across IDBs, $\theta_{\mathrm{av}}{ }^{\mathrm{IDB}}$, increases much slower and remains low in angle from small to large strain compared to GNBs (compare Figs. 7 and 5). The spacing of IDBs, $D_{a v}{ }^{\text {IDB }}$, decreases with increasing strain (Fig. 7). No saturation of angle or spacing is observed. At the largest strain, rather than enclosing equiaxed cells, the IDBs simply bridge across the GNBs forming a bamboo-like structure (Fig. 8). This single volume across a cell block at large strain contrasts with the two or so cells more typical of small strain cell blocks (Hughes and Hansen 2000). 


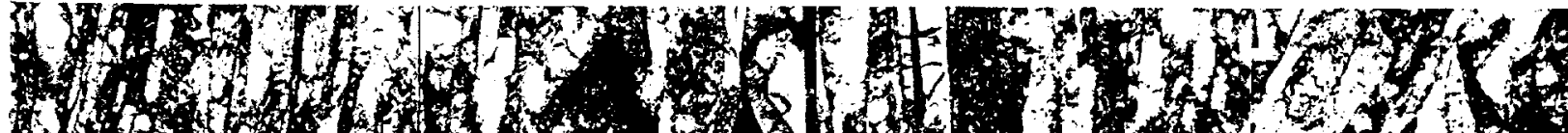

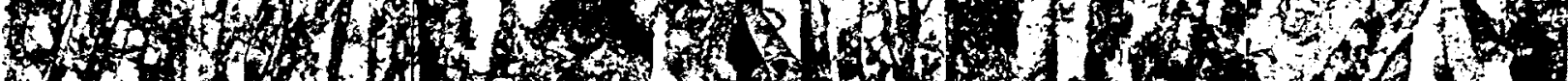

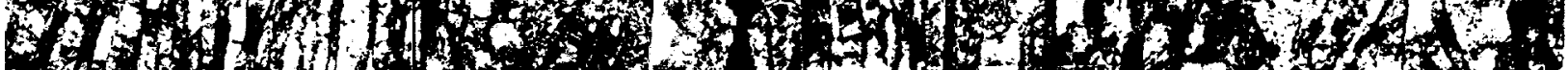

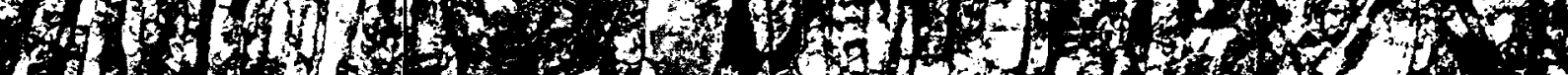

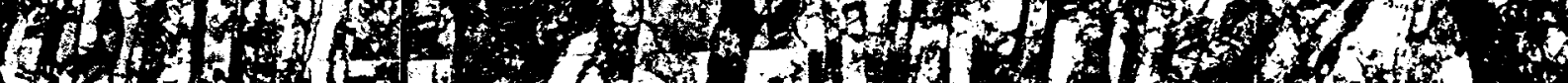

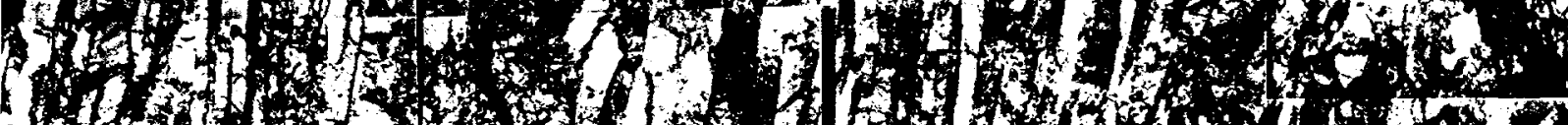

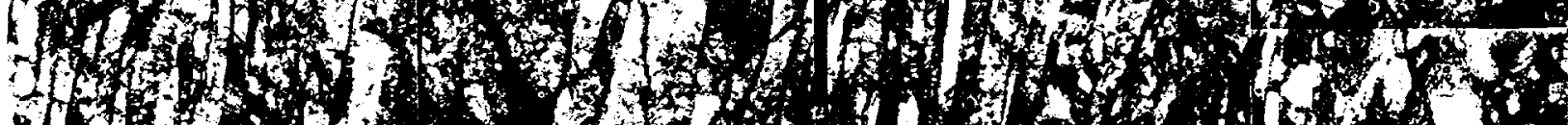

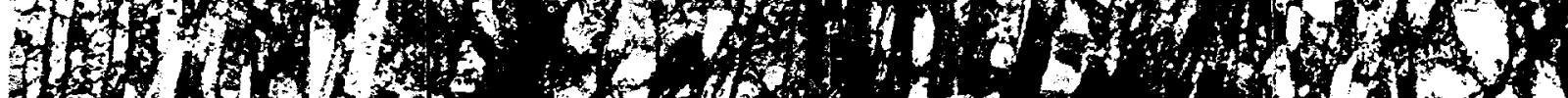

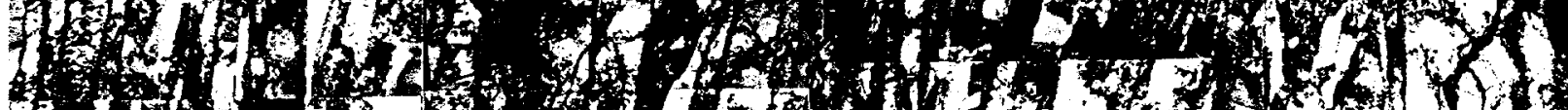

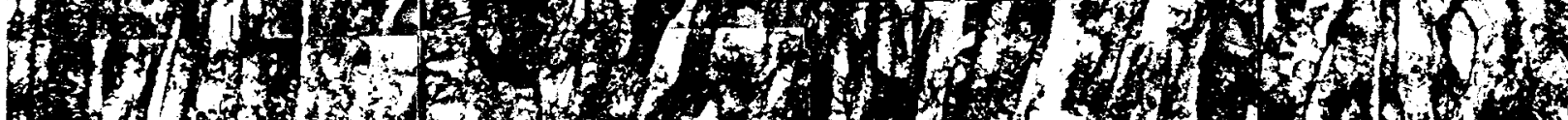

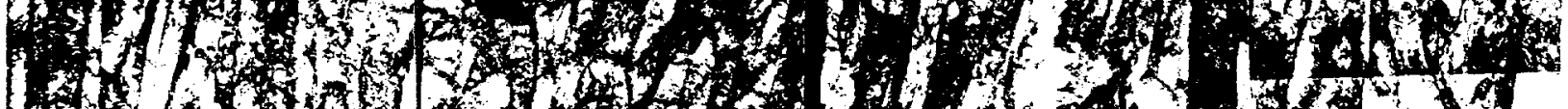

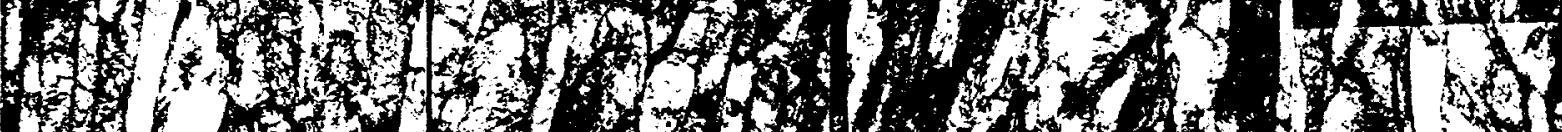

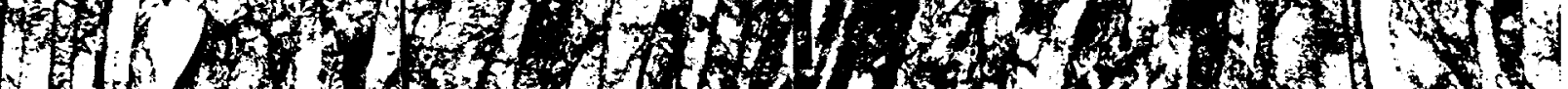
(1)

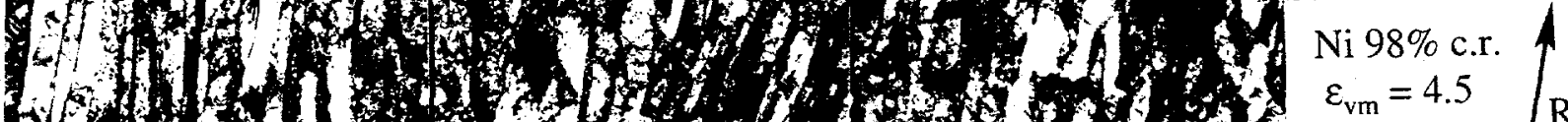
6.

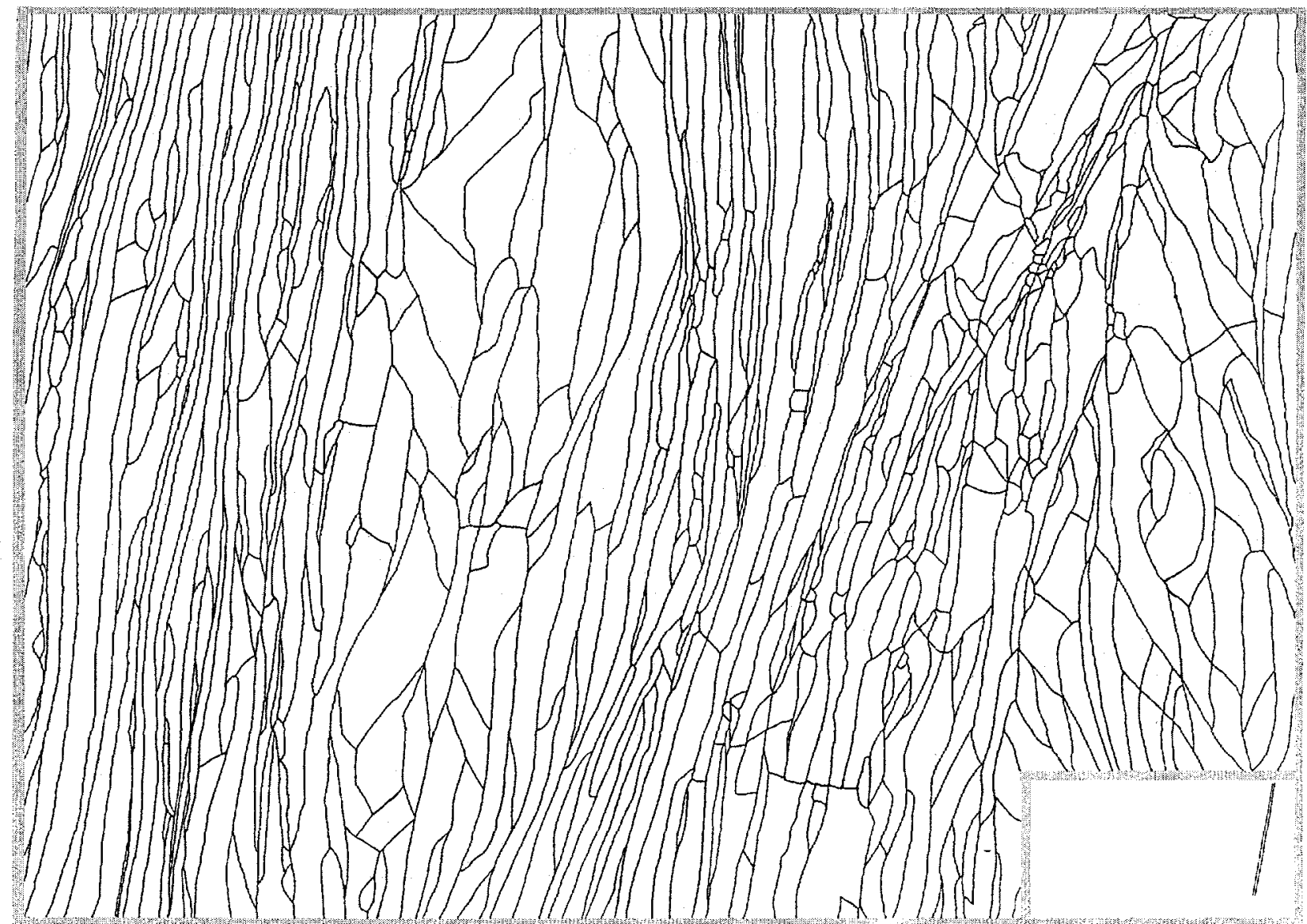

Fig. 4. Caption on opposite page. 
Fig. 4. Opposite page. Microstructure in nickel following $98 \% \mathrm{cr}\left(\varepsilon_{\mathrm{vM}}=4.7\right)$. Very long well developed GNBs (i.e., LBs) are nearly parallel to the RD with short bamboo IDBs bridging between them. (a) TEM micrograph in the longitudinal section (Hughes and Hansen 1993). (b) tracing of just the GNBs shown in (a). The inclined marker is $1 \mu \mathrm{m}$ long and indicates the RD.

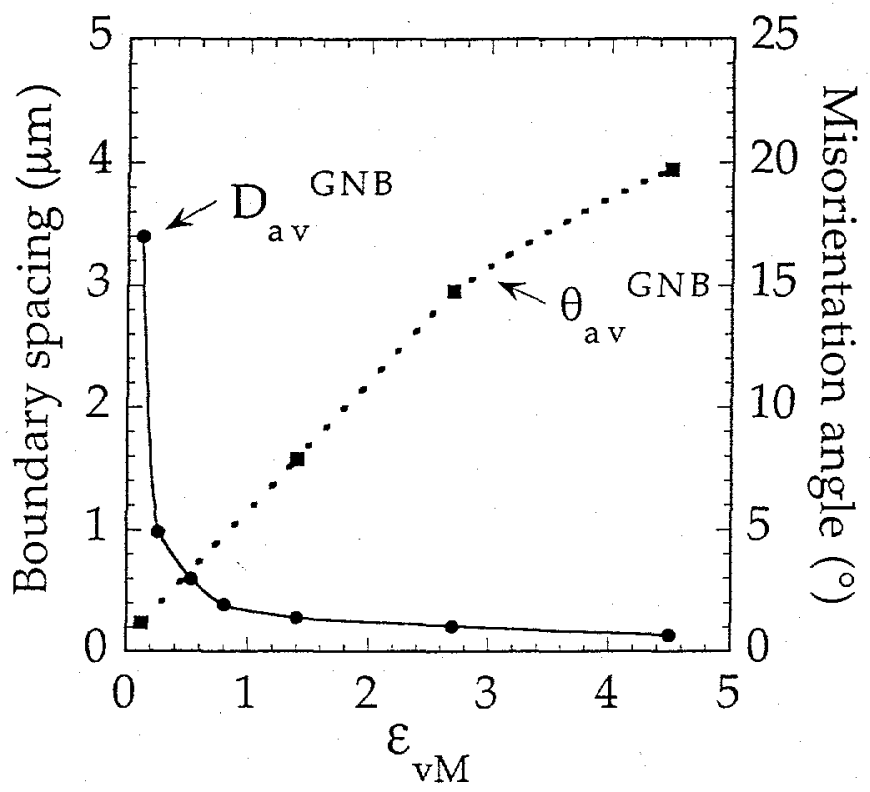

Fig. 5. Decrease in average boundary spacing and increase in misorientation angle across GNBs as a function of strain in cold rolled nickel. Note that neither the spacing nor the angle has saturated at large strain (Hughes and Hansen 2000).
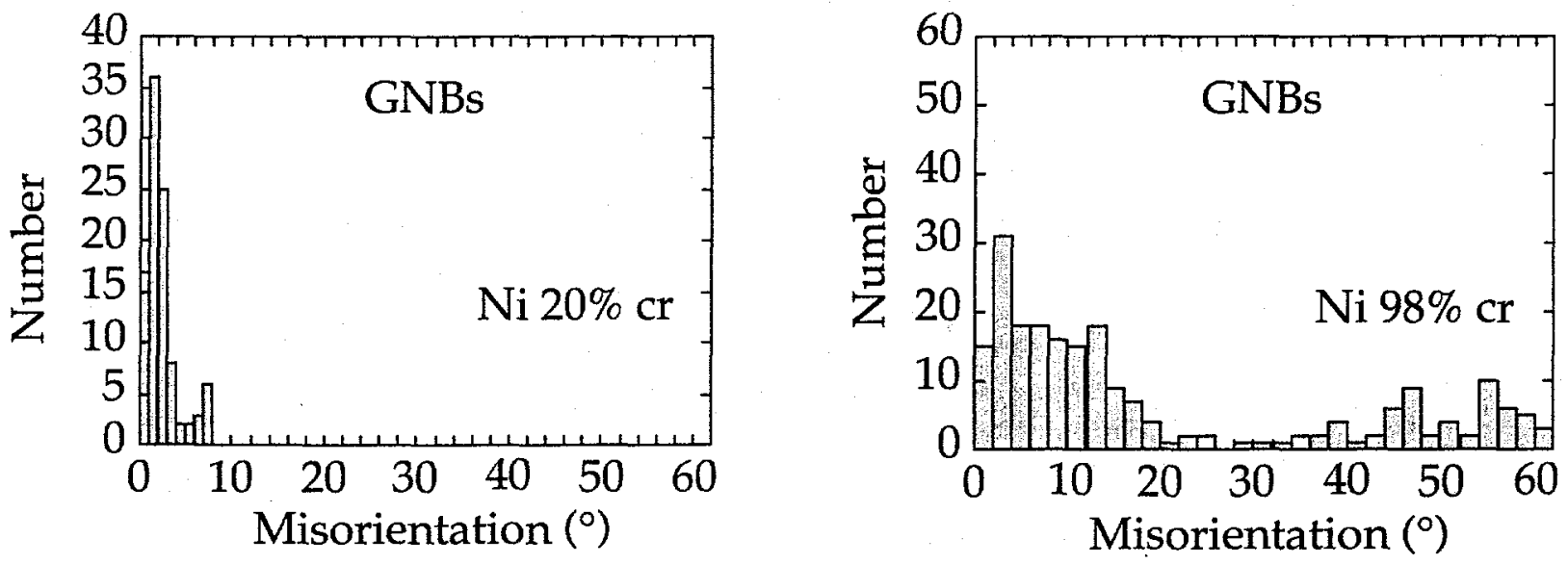

Fig. 6. Histograms showing the distribution of GNB misorientation angles as a function of strain in nickel, (a) $20 \% \mathrm{cr}$ (b) $98 \% \mathrm{cr}$. Note that this distribution includes both low and high angles.

Fig. 7. Decrease in average boundary spacing and increase in misorientation angle across IDBs as a function of strain in cold rolled nickel (Hughes and Hansen 2000).

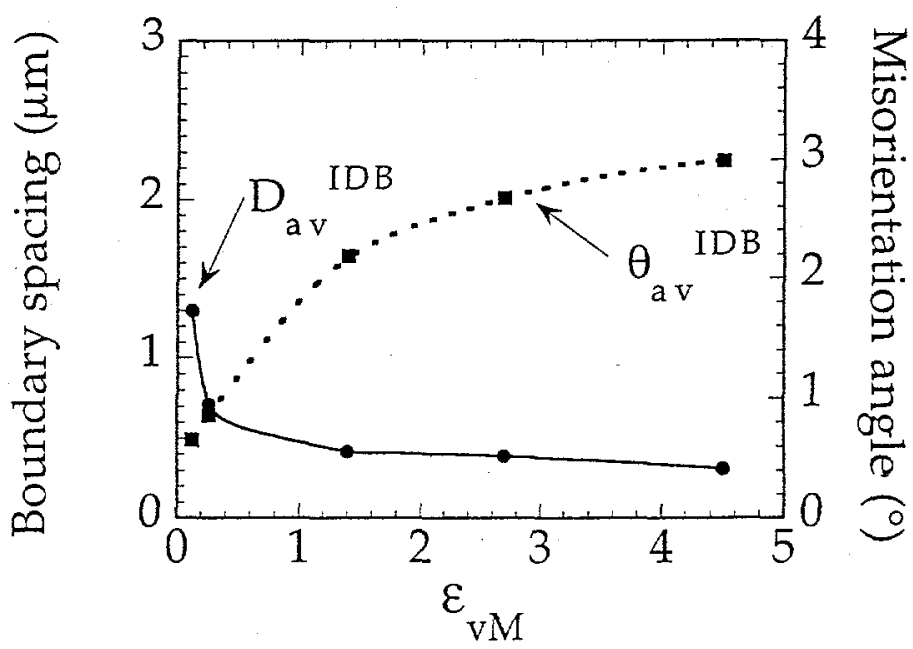


This double classification of boundaries is supported by:

I) The clear morphological differences between the extended GNBs and the short rounded IDBs.

II) The different rates of development of the misorientation angles and spacing with increasing strain.

III) Their differences with respect to the similarity property, $\mathrm{D}_{\mathrm{av}}{ }^{\mathrm{IDB}} \theta_{\mathrm{av}}{ }^{\mathrm{IDB}}=$ constant with increasing strain (Hansen and Hughes 1995).

IV) The finding that distributions of individual $\mathrm{D}^{\mathrm{IDB}}, \mathrm{D}^{\mathrm{GNB}}$ and $\theta^{\mathrm{IDB}}$ in a given sample for different strains, materials and temperatures can be scaled into universal distributions by their averages (Fig. 9a and b) (Hughes , Chrzan, Liu and Hansen 1998; Hughes and Hansen 2000; Godfrey and Hughes 2000b).

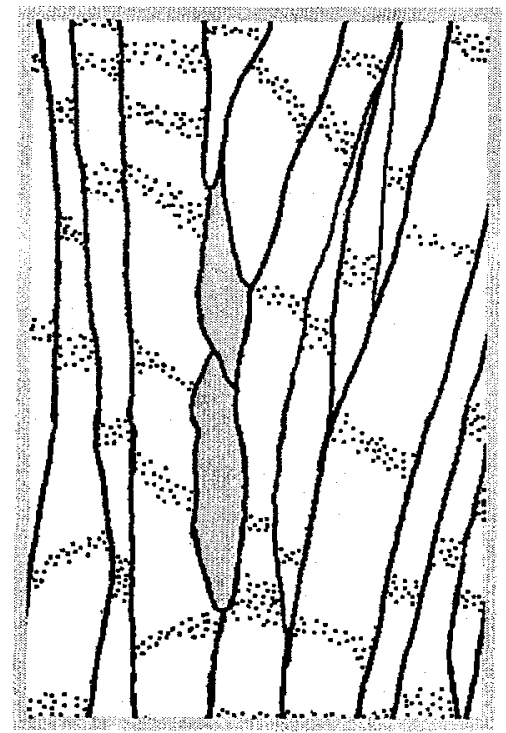

Fig. 8. Tracing of TEM . micrograph of pure nickel following $90 \%$ reduction $\left(\varepsilon_{\mathrm{vM}}=2.7\right)$ by cold rolling in which the bamboo IDBs are shown with a stippled band bridging between the GNBs (Hughes and Hansen 2000).

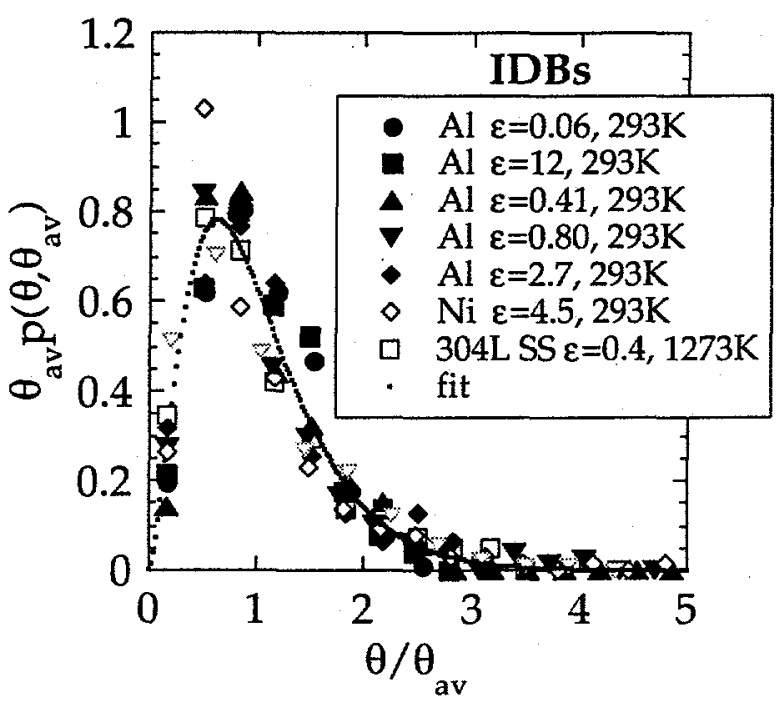

a)

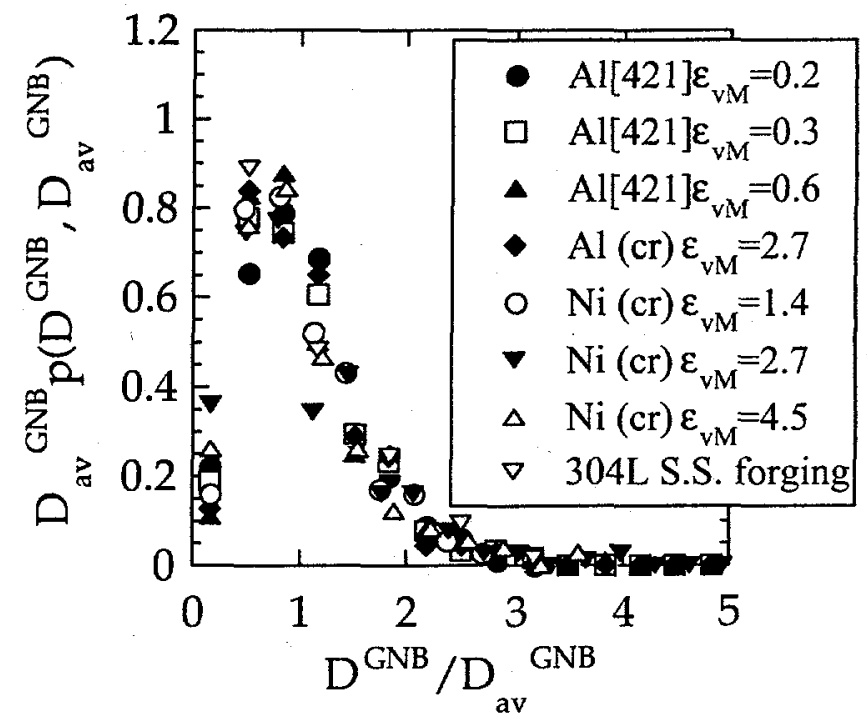

b)

Fig. 9. (a) Probability distributions, $\mathrm{P}\left(\theta, \theta_{\mathrm{av}}\right.$, $)$ for IDB misorientation angles $\theta$. (b) Scaled distributions as a function of the ratio of $\theta$ to $\theta_{a v}$, for several systems and parameters (Hughes et al. 1998). b) Probability distributions, $P\left(D^{\mathrm{GNB}}, \mathrm{D}_{\mathrm{av}}^{\mathrm{GNB}}\right)$ for $\mathrm{GNBs}$ scaled by the ratio of $\mathrm{D}^{\mathrm{GNB}}$ to $\mathrm{D}_{\mathrm{av}}{ }^{\mathrm{GNB}}$ data from (Godfrey and Hughes 2000; Hughes and Hansen 2000). 
Deformation microstructures and selected examples of their recrystallization

\section{SELECTED ILLUSTRATIONS OF DEFORMED STRUCTURES AND THEIR RECRYSTALLIZATION}

In the next section three examples are used to demonstrate the general principles of the microstructural analysis. The first two examples will emphasize the deformation structures in single and bicrystals, since the history of the crystal, including the slip pattern and the crystal rotations, may be quantitatively tracked. A further advantage is that grain boundaries are avoided or restricted, allowing one to consider subsequent nucleation events within the deformed structure. As a last example, the generality of these analyses is explored using the practical example of a commercial forging.

3.1 A macro-scale layered structure. Single crystals compressed along the [421] direction provide an extreme example of the development of macro-scale bands during deformation. This orientation which lies in the middle of the standard stereographic triangle is highly oriented for single glide on one slip system. Single glide dominates on average for much of the crystal volume as evidenced by the quantitative measures of the oval external sample shape change of the starting right circular cylinder and by the direction of crystal rotations (Hughes and Godfrey 1998). The crystal volume or regions associated primarily with single glide will be referred to as the matrix region.

Furthermore, TEM reveals that the cell blocks in this region have GNBs nearly parallel to the primary slip plane forming flat slabs (Fig. 10). This morphology is a typical result for single glide oriented crystals (Steeds 1966). The spacing and misorientation angle of these boundaries is given in Table 1. The distributions of misorientation angles and spacing for the boundaries in these cell block follow scaling behavior like their polycrystal counterparts, but develop smaller misorientations than the average grain orientation in a polycrystal grain (e.g., Fig. 9b) (Godfrey and Hughes 2000b).

Alternating in layers within this matrix region are macro-scale bands millimeters to $100 \mu \mathrm{m}$ long by ten to $100 \mu \mathrm{m}$ wide (Fig. 2). Recall that these macros-scale bands develop as result of large spatial alterations in the slip pattern that accommodate the constraint of the compression platen in this single glide crystal. Thus the crystal volume defined by the bands develops a different dislocation structure with respect to the cell block morphology and the magnitude of the boundary angle and spacing compared to the matrix. This difference is shown clearly by TEM, Fig. 10. The macro-scale bands comprise about $10 \%$ of the structure. These bands are highly inclined to the primary plane GNBs, intersecting those GNBs along an axis which is parallel to the compression plane and perpendicular to the extension direction. These bands contain cell blocks with a nearly square cross section and two sets of parallel GNBs (Fig. 10), one of which is near the primary plane. The long axis of the cell blocks is parallel to the intersection axis between the bands and the primary GNBs. TEM (Fig. 10) shows that there is a very diffuse transition between the macro-scale band and the matrix. No single boundary exists to demarcate the two regions. The two sets of GNBs within the macro-scale bands have higher misorientation angles, and smaller spacings than those in the matrix, see Table 1 . The average orientations in the band and matrix differ by $\sim 25^{\circ}$ following a strain of 0.45 with the main spread of orientations occurring about a rotation axis parallel to the compression plane and perpendicular to the extension direction (Fig. 11a). High angle boundaries, $>15^{\circ}$, are also found within the macro-scale bands already at this strain level.

Note that these results for the [421] single crystals are also quantitatively similar to those observed in a [421] oriented crystal within a compressed bicrystal. The only difference arising in some rearrangement of the distribution of macro-scale bands in the crystal to accommodate the bicrystal boundary. 


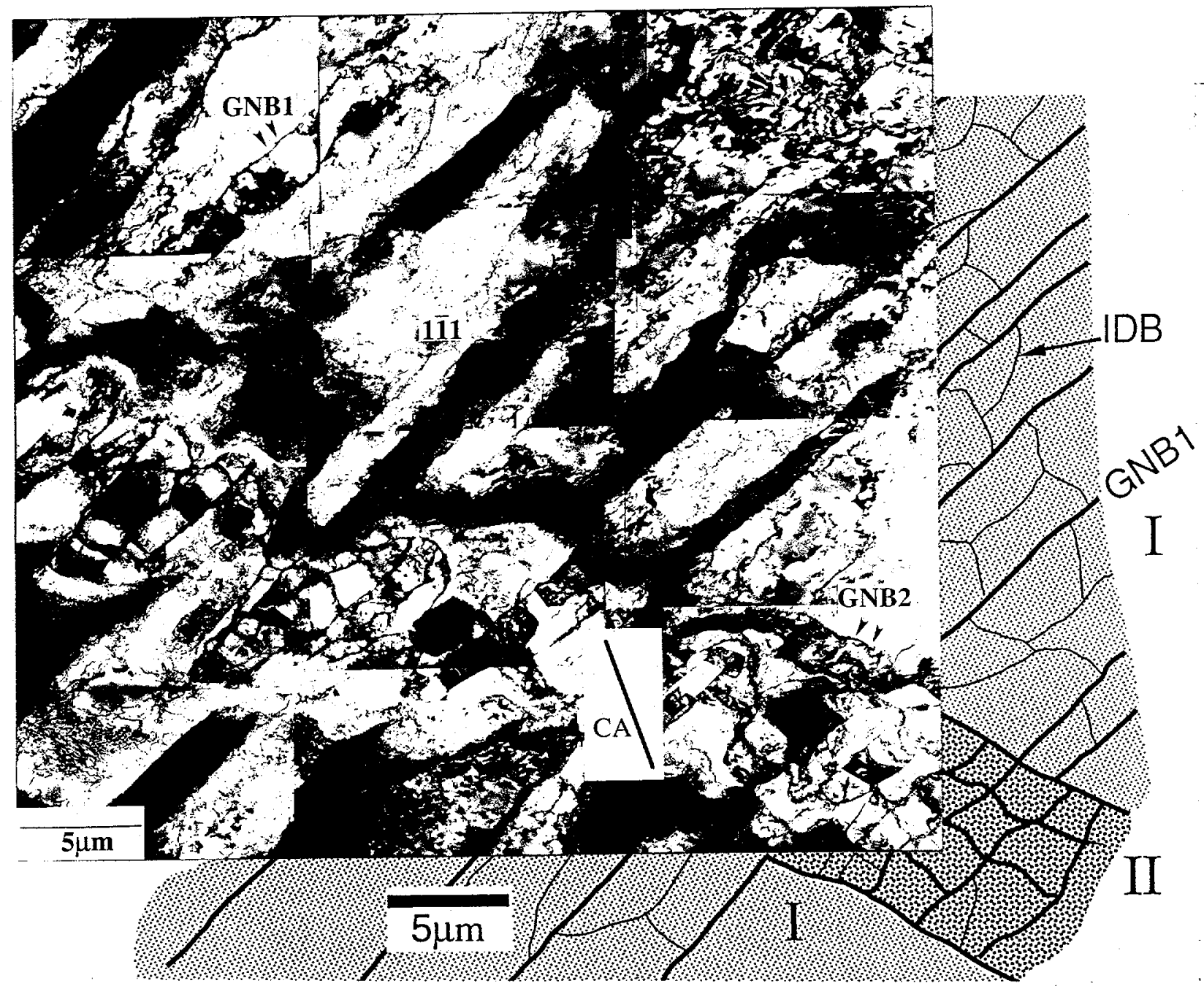

Fig. 10. TEM micrograph of an aluminum [421] single crystal compressed at room temperature to a strain of $\varepsilon=0.3$ (section includes the compression axis, $\mathrm{CA}$ ). Cell blocks delineated by planar GNBs (lying nearly parallel to the primary slip planes) can be seen in regions I. Long macroscopic secondary bands form regions II. In each region IDBs are seen within the cell blocks (Godfrey and Hughes 2000).

The stored energy per unit volume in the different regions can be estimated based on contributions from both the GNBs and the IDBs using the Read-Shockley equation and the boundary area per unit volume, $S_{v}$ (Table 1) (Read and Shockley 1950; Humphreys 1997): $E_{v}=\left\{\left[S_{v}{ }^{\mathrm{IDB}} \theta_{\mathrm{av}}{ }^{\mathrm{IDB}} / \theta_{\mathrm{c}}\left(1-\ln \theta_{\mathrm{av}}{ }^{\mathrm{IDB}} / \theta_{\mathrm{c}}\right)\right]+\left[\mathrm{S}_{\mathrm{v}}{ }^{\mathrm{GNB}} \theta_{\mathrm{av}}{ }^{\mathrm{GNB}} / \theta_{\mathrm{c}}\left(1-\ln \theta_{\mathrm{av}}{ }^{\mathrm{GNB}} / \theta_{\mathrm{c}}\right)\right]\right\} \gamma_{\mathrm{m}}$, in which $\theta_{\mathrm{c}}$ is the critical angle at which a boundary becomes a high angle boundary, i.e., $15^{\circ}$, and $\gamma_{\mathrm{m}}$ is the energy per unit area of a general high angle boundary. At $\varepsilon_{\mathrm{vm}}=0.3$ the ratio of stored energy between these layered regions is estimated to be about six.

Consequently this difference in cell block morphology, boundary angle and spacing creates extremely large differences in stored energy between the matrix and the bands. All three parameters are equal contributors. Note that the cell block morphology and spacing can only be determined from TEM measurements.

This layered structure strongly directed the development of the annealed and recrystallization microstructures during heat treatment (Godfrey and Hughes 2000a). This development can be followed by considering the [421] single crystal compressed to $\varepsilon_{v M}=0.45$ and subsequently annealed at $150^{\circ} \mathrm{C}$ for different times and then quenched to room temperature. 


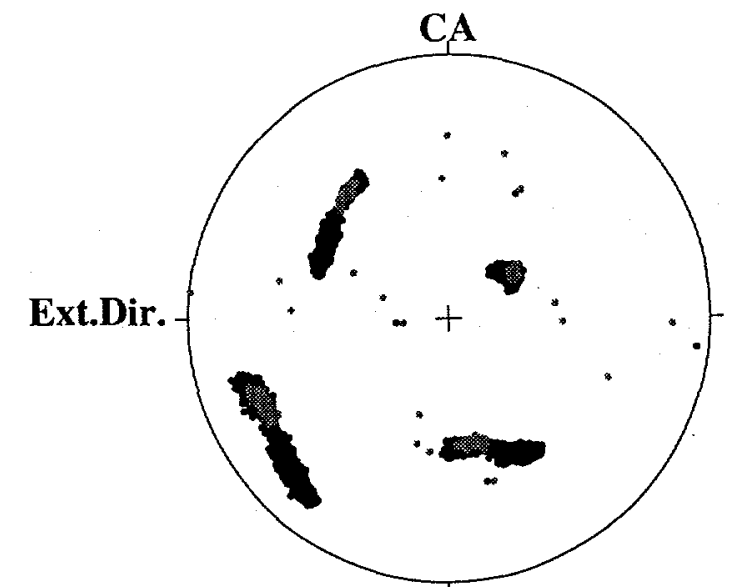

a)

Fig. 11. Pole figures $\{111\}$ showing local orientations in (a) the as deformed and (b) as deformed plus annealed (b) [421] oriented single crystals and bicrystal.

Table 1. Parameters associated with the cell block structures of the [421] single crystal compressed to $\varepsilon_{\mathrm{vM}}=0.3$.

\begin{tabular}{|c|c|c|c|c|c|c|c|}
\hline Region & $\begin{array}{l}\mathrm{D}_{\mathrm{av}}^{\mathrm{GNB}} \\
(\mu \mathrm{m})\end{array}$ & $\begin{array}{c}\mathrm{S}_{\mathrm{v}}^{\mathrm{GNB}} \\
\left(\mu \mathrm{m}^{-1}\right)\end{array}$ & $\begin{array}{c}\theta_{\mathrm{av}}^{\mathrm{GNB}} \\
\left(^{\circ}\right)\end{array}$ & $\begin{array}{l}\mathrm{D}_{\mathrm{av}}^{\mathrm{IDB}} \\
(\mu \mathrm{m})\end{array}$ & $\begin{array}{c}S_{v}{ }^{I D B} \\
\left(\mu \mathrm{m}^{-1}\right)\end{array}$ & $\begin{array}{c}\theta_{\mathrm{av}}^{\mathrm{IDB}} \\
\left(^{\circ}\right)\end{array}$ & $\begin{array}{c}\mathrm{E} / \gamma_{\mathrm{m}} \\
\left(\mu \mathrm{m}^{-1}\right)\end{array}$ \\
\hline matrix & 2.7 & $0.37 *$ & 1 & 3.4 & $0.46^{* * * *}$ & 0.6 & 0.17 \\
\hline $\begin{array}{l}\text { macro- } \\
\text { scale band }\end{array}$ & 1.3 & $1.5 * *$ & 4 & $\sim 3.4$ & $\sim 0.46^{* * *}$ & $\sim 0.6$ & $\sim 1$ \\
\hline
\end{tabular}

The microstructure inside these macro-scale bands has a high stored energy and contains deformation induced high angle boundaries, whereas the matrix on either side of the bands has a much lower stored energy and contains only low angle boundaries. The macro-scale bands thus have a structure that is much more conducive to nucleation and recrystallization. Consequently, a two step recrystallization process is observed in these layered structures as follows (Fig. 12).

I) After one to ten minutes at $150^{\circ} \mathrm{C}$, nucleation of new grains only occurs within the macro-scale bands. This nucleation occurs both within and at the edge of the bands. Nucleation may occur by several processes either in isolation or combination. These processes are subgrain growth, subgrain coalescence and strain induced boundary migration (SIBM), see the schematic Fig. 12a and $b$ and optical micrograph Fig. 13. The nuclei grow along the length of the macro-scale bands thereby creating a bamboo structure.

II) These nuclei /grains thereby reduce the stored energy within the macro-scale bands creating the potential for the high angle boundaries to migrate from the macro-scale bands into the matrix regions by SIBM, Fig. 12c.

These observations indicate that the presence of the macro-scale bands with high misorientations and stored energy are strong nucleation sites. The quick nucleation and growth within these bands further suggests that recrystallization is occurring at a higher rate than the recovery of the high stored energy structure. Similar results in the bicrystal also indicate that these bands are more conducive to nucleation than the original bicrystal boundary. This result is in accord with the observations in the cold deformed stage showing that gradient of stored energy in the region around the boundary in the bicrystal was not very large. Similar behavior was reported in (Liu, Hu and Hansen 1995) for a differently oriented bicrystal. 
a)

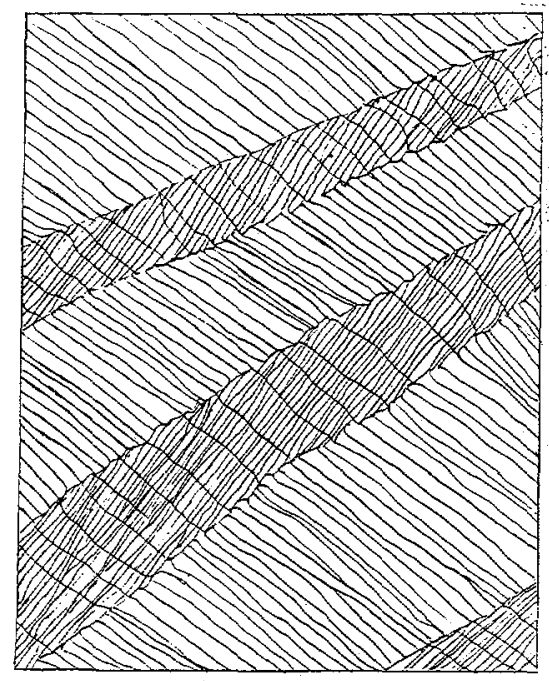

b)

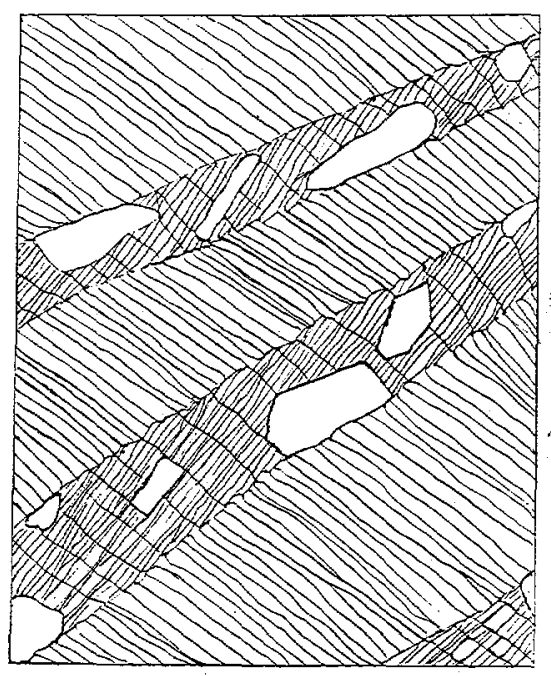

c)

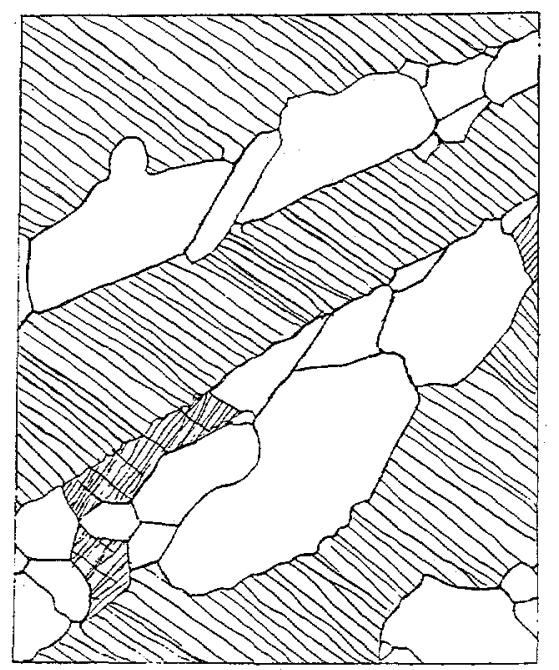

Fig. 12. Schematic drawing of the two stage recrystallization process in a layered structure. (a)Deformed state: two macroscale bands. (b) Annealed state first stage: growth of recrystallized grains in macroscale bands. (c) Annealed state second stage: growth of grains into matrix.

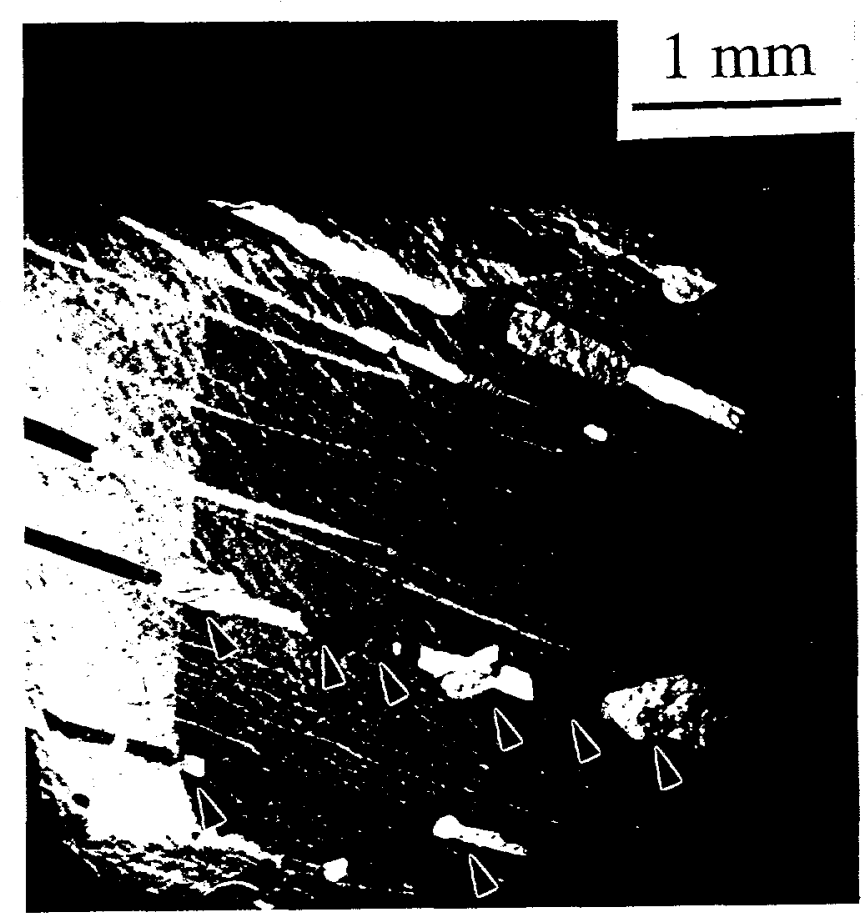

Fig. 13. Aluminum single crystal first compressed to a strain of $\varepsilon_{\mathrm{vM}} \sim 0.45$ with the [421] axis initially parallel to the compression axis and subsequently annealed at $373 \mathrm{~K}$ for 900 seconds. Polarized light micrograph shows nuclei (marked by arrows) originating within and at the edges of the macro-scale bands. 
Additionally the crystal orientations of both the as deformed and recrystallized state were measured using electron back scattered patterns (EBSP) in the scanning electron microscope and Kikuchi patterns in the TEM. It was observed that most of the recrystallized grains had orientations that were unrelated to the main scatter of orientations in the deformed state (Fig. 11). While one cannot rule out that this result could be due to growth of nuclei arising from surface damage, even during careful sample preparation, the association of these orientations with the location of the prior macro-scale bands points to a native source within these bands.

Careful local measurements by EBSP of the deformed state revealed rare extreme orientations (Fig. 11a) in the macro-scale bands, especially at the intersection of two bands. These extreme orientations only comprised about $1 \%$ of the orientations in the macro-scale bands, or $<0.01 \%$ of

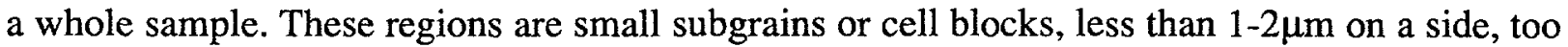
small to be considered as preexisting nuclei. While these extreme deformed orientations fit within the wide scatter of recrystallized grains (Fig. 11b), they did not specifically match one to one an orientation of a recrystallized grain.

These results show that the deformed state is a likely source of the recrystallized grains of unusual orientation. However the lack of a one to one match prompts the question of whether all the recrystallized orientations can be ascribed to the deformed state. The dominance of these unusual orientations is also an interesting feature of the recrystallized state.

3.2. Nonlayered structures and decreasing levels of heterogeneity. A spectrum of deformation microstructures is produced by deforming single crystals with different starting orientations, e.g., (Gottler 1973; Kawasaki 1979; Kawasaki and Takeuchi 1980; Malin et al. 1981; Becker et al. 1991; Blicharski, Becker and Hu 1993; Driver, Juul Jensen and Hansen 1994; Godfrey, Juul Jensen and Hansen 1998b). These various structures affect the subsequent recrystallization, e.g., (Driver 1995; Godfrey, Juul Jensen and Hansen 1995; Ferry and Humphreys 1995; Huang, Humphreys and Ferry 2000; Huang and Humphreys 2000; Godfrey, Juul Jensen and Hansen 2000); see also articles by the same authors in these proceedings. The level of heterogeneity may be high, especially in the layered structures developed in crystals whose nominal deformed orientations differs substantially from its initial orientation. Examples include the previous compressed [421] crystal and channel die deformed rotated cube and cube oriented crystals (Becker et al. 1991; Liu and Hansen 1998). At the other extreme, the structure may be fairly homogeneous throughout. An example is the channel die or rolled $\{110\}<112>$ crystal in which the nominal orientation is maintained during deformation, the slip pattern distributed more uniformly, and only small boundary misorientations and low stored energy develop (Malin et al. 1981; Driver 1995; Godfrey, Juul Jensen and Hansen 1998a).

A middle range of heterogeneities is found in crystals that develop some macroscale divisions of the slip pattern but at the same time maintain their nominal orientation, thus combining characteristics from both the most heterogeneous and most homogeneous crystals. Examples include the $\{112\}<111>$ crystal deformed by channel die or rolling (Morii and Nakayama 1981; Driver et al. 1994; Wagner, Engler and Lucke 1995; Godfrey et al. 1998b) and the $\{123\}<634>$ or $\{123\}<412>$ orientations deformed by channel die (Liu et al. 1995).

Channel die deformed crystals oriented $\{112\}<111>$ develop spatial heterogeneities corresponding to regions in which an initial set of cell blocks have been modified by strongly intersecting glide compared to regions where they have not. Initially this glide may be distinguishable as the coarse glid of S-bands (Hughes and Hansen 1993) on a local _scale. 


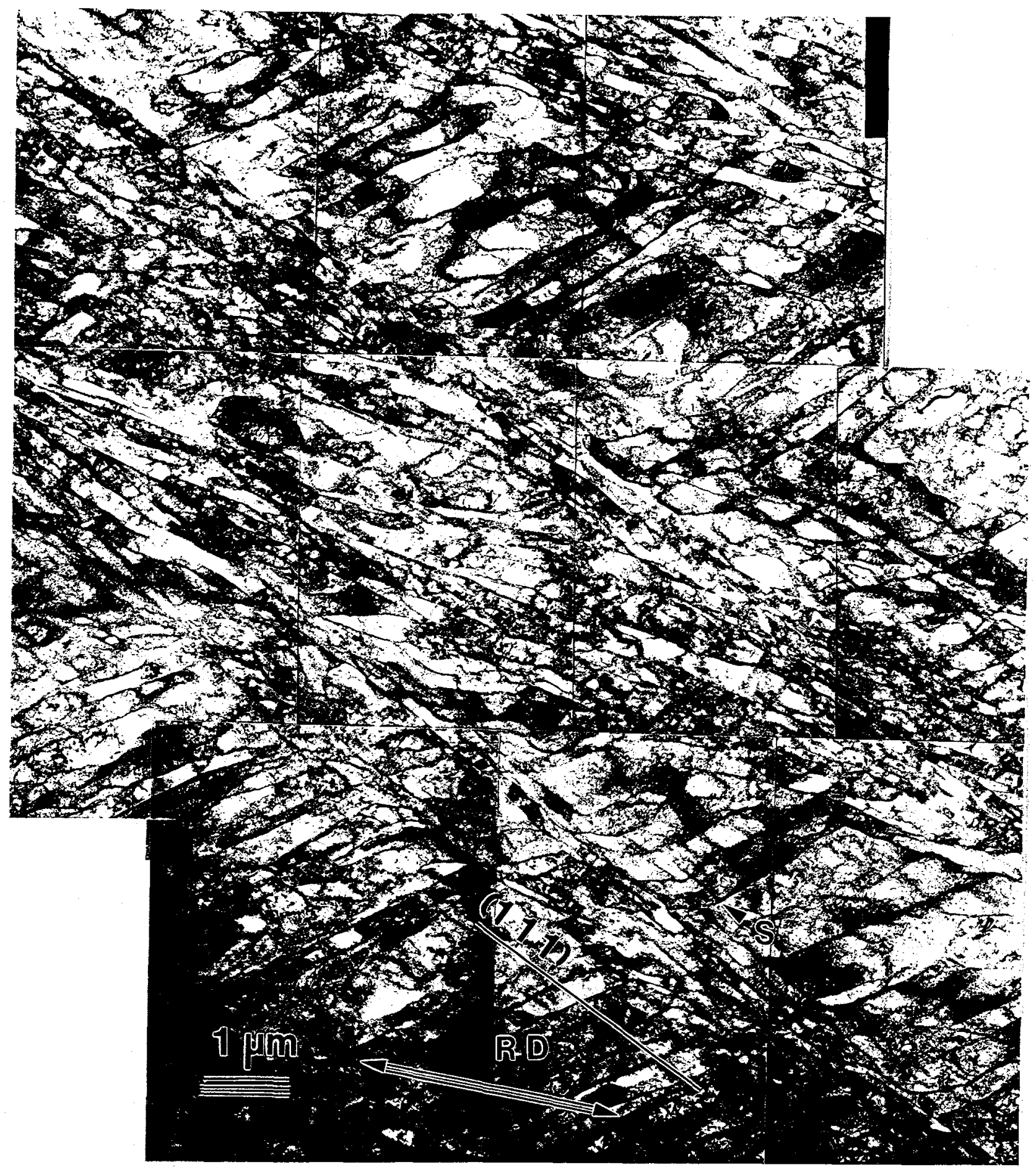

Fig. 14. S-bands forming narrow localized glide bands along the slip plane trace in a cold rolled nickel polycrystalline grain following $70 \% \mathrm{cr}$.

However extensive intersecting glide creates new sets of cell blocks highly inclined to the first. These regions have been called localized glide bands (Godfrey et al. 1998b). A weaker example of this development is also observed in $\{123\}<634>$ crystals (Liu et al. 1995). Figure 14 shows an example of this type of structure albeit forming in a polycrystaline grain between the $\{112\}<111>$ and $\{123\}<634>$ orientations following $70 \% \mathrm{cr}$ nickel. S-bands features are still clearly visible in this photo. 
The magnitude of the heterogeneity between the initial set of cell blocks and those in the localized glide bands is defined by the spreads in average orientations and rotation axes, the magnitude of the GNB misorientation angles and the boundary plane of the GNBs, their spacing, and the stored energy. The width and length of the localized glide band is also important. It is observed that the localized glide bands in the $\{112\}<111>$ crystal develops more directional orientation spreads, larger misorientation angles, as well as being of larger width and length compared to those in $\{123\}<634>$ or to a more random grain in a polycrystal.

Nucleation occurs rapidly within the high stored energy regions of the localized glide bands upon annealing, whereas growth into the regions outside these is much slower in the $\{112\}<111>$ (Liu et al. 1995; Godfrey et al. 1995). This difference may be related not only to stored energy differences but also to the morphology of the localized glide bands with their extended GNBs parallel to the band and also due to orientation pinning (Doherty, Samajdar, Necker, Vatne and Nes 1995; Juul Jensen 1995) from segmented alternating boundary misorientations found in nuclei that develop in such bands (Rosen, Juul Jensen, Hughes and Hansen 1995), as suggested in (Godfrey et al. 1995) The recrystallized crystal orientations are related to orientations at the far edge of the range of deformed orientations in the bands.

In contrast to the $\{112\}<111>$ orientation, the heterogeneities in the localized glide regions in the $\{123\}<634>$ orientation are weak sites for nucleation and recrystallization is much slower (Liu et al. 1995).

3.3. Application of the microstructural analysis to a commercial forging. A last example illustrates the practical case of high temperature forging of 304L stainless steel (S.S.). During the process of qualifying two new forging vendors, A and B, it was noted that macro-etched cross-sections of the forging from vendor A showed an anomalous grain structure, whereas the forging from vendor B did not. Since the grain size distribution, grain shape and a uniform residual dislocation structure are important requirements for the application of this forging, an investigation was made into the cause of this difference. This investigation involved a combination of finite element (FEM) analysis of the forging process and a post mortem microstructural analysis including optical, SEM and TEM techniques. Furthermore this problem presented a good opportunity to apply and evaluate the microstructural analyses and principles developed for the pure fcc metals of medium to high stacking fault energy with regard to a complex process and material.

In this austenitic steel, the substitutional alloying additions of $18 \% \mathrm{Cr}$ and $8 \% \mathrm{Ni}$, nominally, to the $\mathrm{Fe}$, plus the trace interstitial elements of $\mathrm{C}$ and $\mathrm{N}$, result in an fcc crystal structure with a low SFE. Both vendors were given compositionally controlled starting heats of 304L S.S., so that differences in starting material were not an issue. The starting grain size of the material is medium small, 30-40 $\mu \mathrm{m}$. Both vendors preheat the steel in a furnace, then forge in warm dies and water quench. This process is repeated multiple times, i.e., stages, to create a desired shape and structure. In between the stages the furnace preheat fully recrystallizes the forging. Only in the final stage is a worked structure retained. While both vendors used the same temperature in the final stage, $1144 \mathrm{~K}$, their forging equipment and forging rate differed. Vendor $\mathrm{A}$ used a hydraulic press with a displacement rate of $2.4-3 \mathrm{~m} / \mathrm{s}$, while $\mathrm{B}$ used a hammer forge with a displacement rate $24-30 \mathrm{~m} / \mathrm{s}$. Although in both cases the forging cools somewhat during forging due to contact with the warm dies, deformation induced temperature increases also occur. Thus the temperature change during forging is roughly -60 to $-120 \mathrm{~K}$ during the process. A smaller temperature drop is estimated for the hammer forging due to its higher rate. The most important difference between the two processes, however, was the number of forging stages and die shapes which influenced the strain in the final stage as estimated by FEM. Vendor A used only 


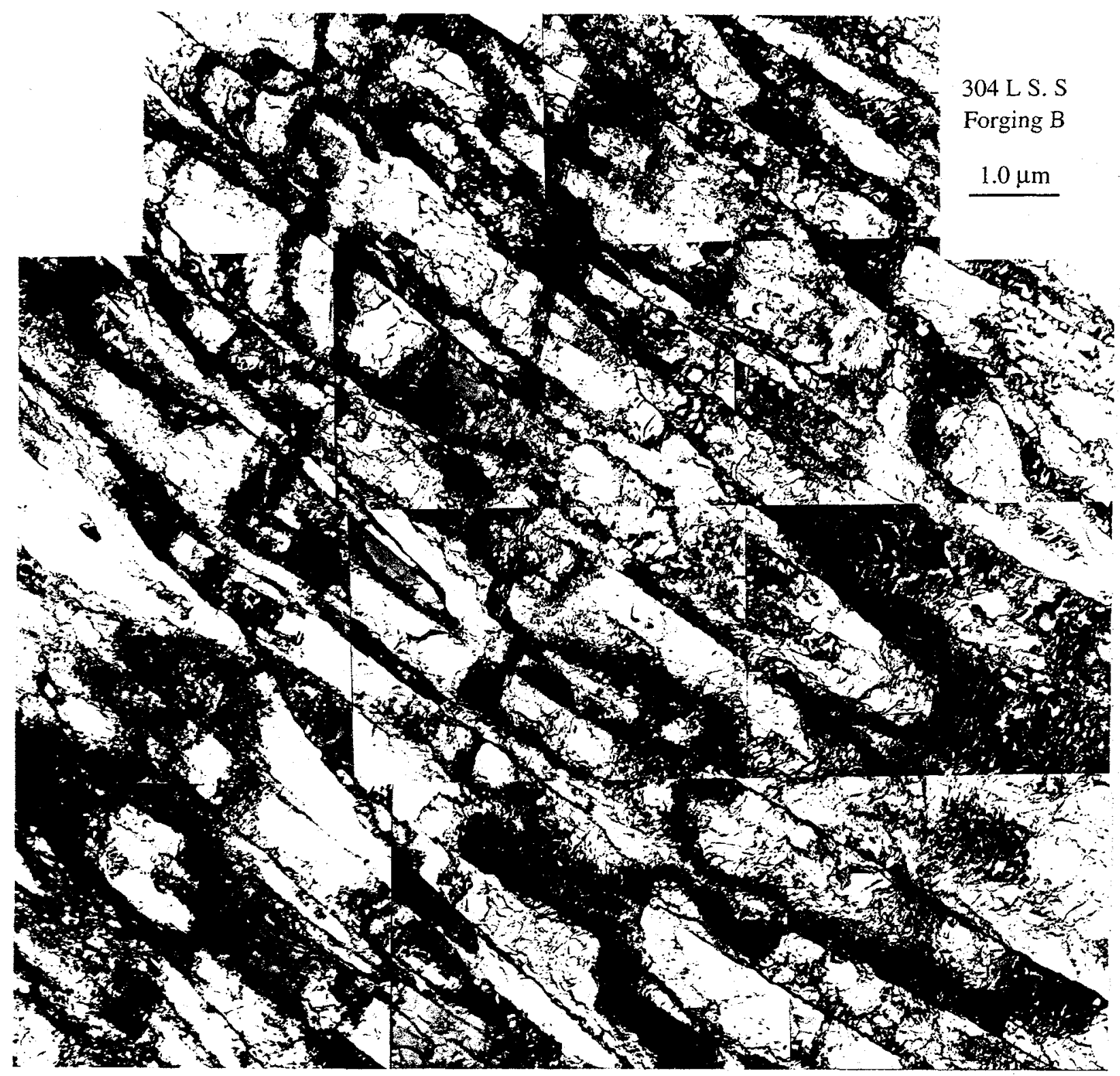

Fig. 15. Following a moderate deformation, $\varepsilon_{\mathrm{vM}} \sim 0.2-0.3$, in a hammer forging of $304 \mathrm{~L}$ S.S. (vendor B), a cell block structure of extended GNBs near the main slip plane is observed.

two stages to obtain the final shape resulting in a forging that was estimated to have undergone a large deformation, $\varepsilon \sim 1.2-2$ in the final stage, whereas B used three stages resulting in a forging that underwent a moderate deformation, $\varepsilon \sim 0.3$ during the last stage.

Transmission electron microscopy reveals that the moderate strain forging B microstructure is a cell block structure of extended GNBs (DDWs/MBs) near the main slip plane (Fig. 15). This structure is very like those in Fig. 3 for nickel and Fig. 10 for the aluminum single crystal. The average spacing of the GNBs is $0.47 \mu \mathrm{m}$. These GNBs have a fairly small average misorientation angle, $2^{\circ}$, with a spread tailing to three times the average (Fig. 16a). Both the average and distribution are consistent with the moderate deformation level and similar to rolled nickel at the same strain, $\varepsilon=0.26$, corroborating the FEM estimates (e.g. compare angular distributions Fig. 16a. with Fig. 6a and averages Fig. 5 for nickel). A further parallel with rolled nickel and other fcc metals is observed with respect to the distribution of GNB spacings. Remarkably when the distributions of individual GNB spacings within the forging are scaled by 


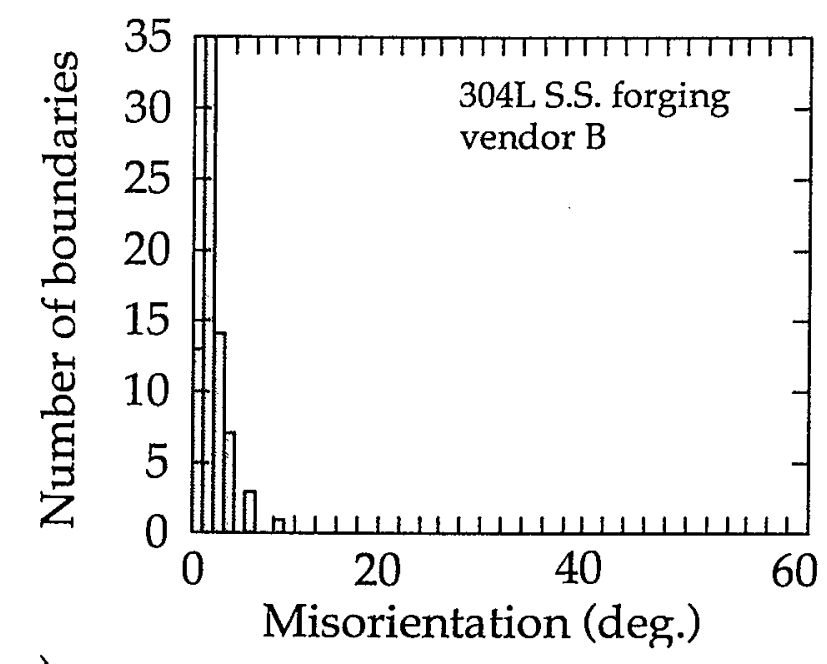

a)

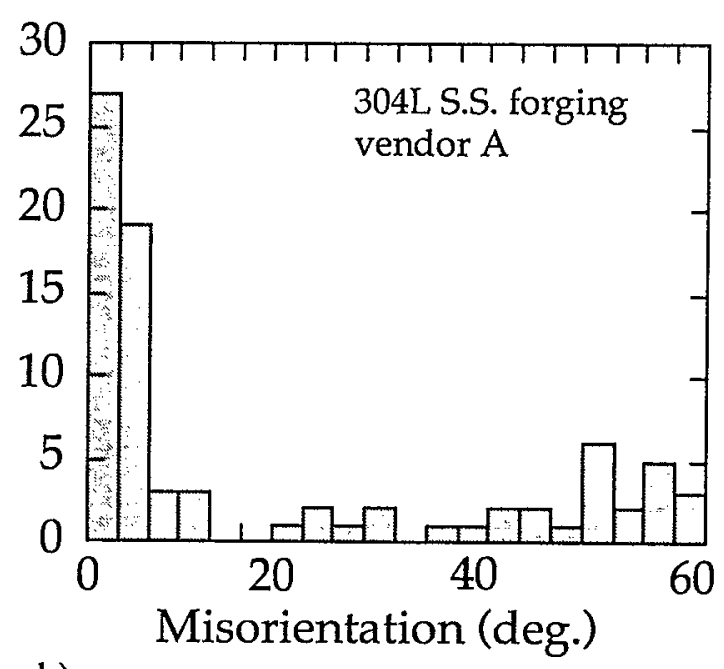

b)

Fig. 16. Histograms showing the distribution of misorientation angles for GNBs in (a) moderate strain 304L S.S. forging. (b) large strain 304L S.S. forging.

the average spacing, the distribution is the same as the universal distribution found for pure metals under more controlled laboratory conditions (Fig. 9b). ${ }^{\dagger}$

None of the medium small grains examined revealed any macro-scale bands or layers. Instead the structures were fairly homogeneous across a grain. Some influence of grain orientation on the cell block morphology was observed with certain grains having two sets of parallel GNBs and others having a single set. This consistent homogeneity is similar to the homogeneity encountered in an $\{110\}<112>$ oriented single crystal. The fairly homogeneous dislocation structure, that was retained following forging $B$, provided the optimum uniformity and increased strength required by the product specifications.

In forging A, TEM revealed a large strain microstructure of finely spaced lamellar boundaries forming cell blocks together with some more equiaxed subgrains (note both are GNBs) (Fig. 17). The LBs are parallel, within $10^{\circ}$, to the shear direction in the forging; compare with Fig. 4 for large strain nickel. Measurements of the misorientation angles across these boundaries reveal a wide spread in angle from high to low, Fig. 16b, like that of nickel rolled to high strain (Fig. 6b) and copper (Sztwiertnia and Haessner 1996). This wide distribution of angles is generally not observed below strains of $\sim 1$. This result again corroborates the FEM strain estimates.

Additionally in large strain forging $\mathrm{A}$, some of the intragranular regions with high angle boundaries contain abnormally large subgrains or incipient recrystallization nuclei, $\sim 1.7 \mu \mathrm{m}$ diameter (Fig. 17 on the right side of the photo). The misorientations around these "subgrains/nuclei" are all higher than $15^{\circ}$, like the high angles observed in the LBs. These high

\footnotetext{
"Note that the high temperature microstructure of cell blocks is different than that observed during cold deformation of 304L S.S.. Deformation at room temperature in this steel creates a structure containing deformation twins, both $\varepsilon$ and $\alpha$ deformation-induced martensite, and more uniformly distributed dislocations instead of dislocations in cell boundaries. This difference occurs because deformation at the higher temperature provides the increased thermal energy to overcome the friction stress in the solid solution as well as the increased three-dimensional mobility for the dislocations to form cell boundaries as in pure metals. These results underline the general significance of the principles developed for analyzing the evolution of deformation microstructures in those deformation regimes where dislocations have three- dimensional mobility.
} 


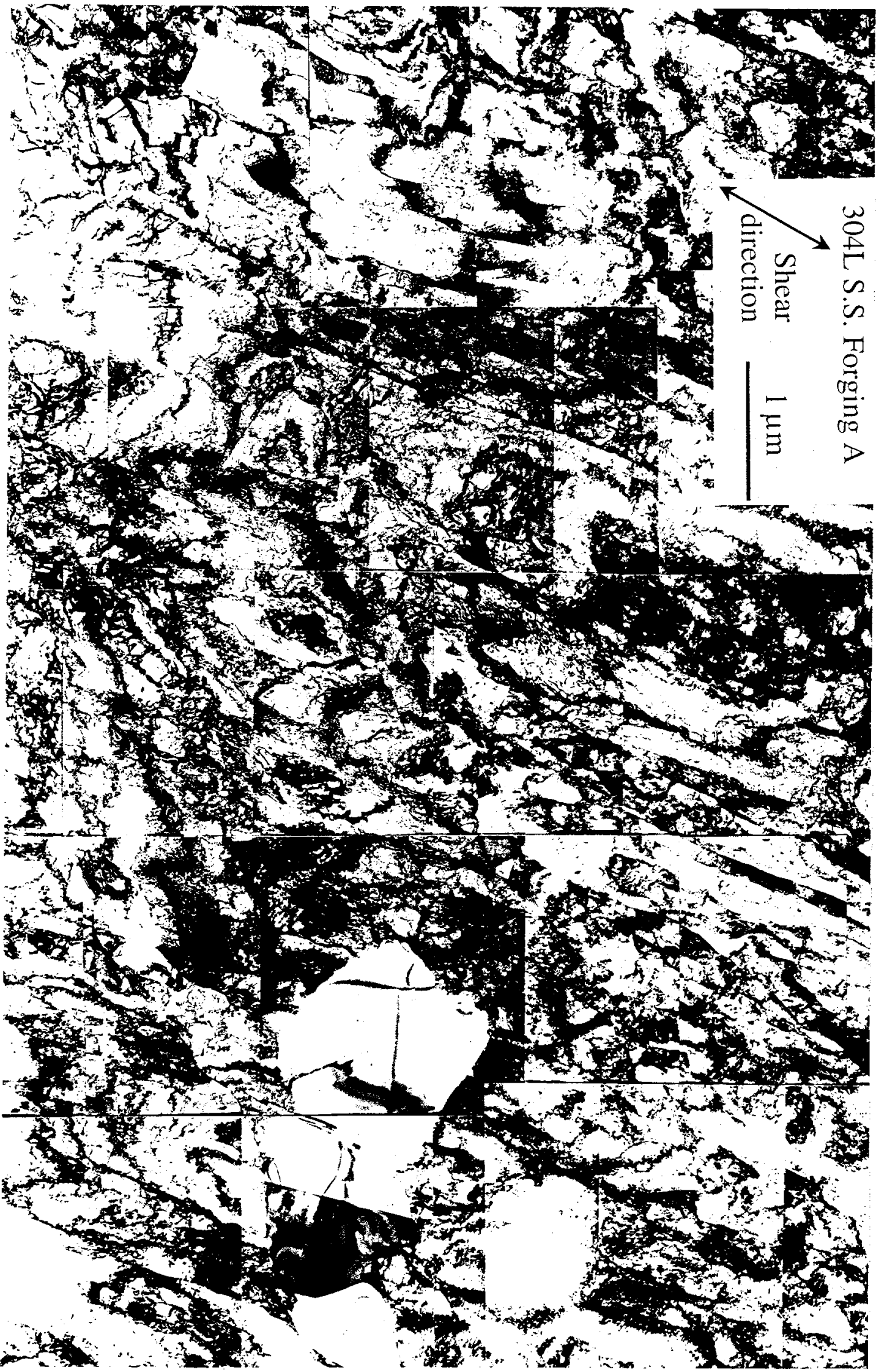

Fig. 17. Following a large deformation, $\varepsilon \sim 1.2-2$, in a of a hydraulic press forging of $304 \mathrm{~L}$ S.S. (vendor A) a microstructure of LBs and subgrains is formed (GNBs). Intragranular regions with high angle boundaries contain abnormally large subgrains or incipient recrystallization nuclei. 
angle "subgrains/nuclei" could have formed either dynamically during the high temperature forge or statically afterwards during the quench. In the TEM foil, these subgrain/nuclei are not associated with a grain boundary. The geometry of the forging deformation results in flat grains with most grain boundaries intersecting the TEM foil at high inclinations. Thus while one cannot preclude an association with a grain boundary, the geometric likelihood is small. Instead it is suspected that these "subgrains/nuclei" are associated with the heterogeneous distribution of deformation induced high angle boundaries. Together the fine distribution of long high angle boundaries and the larger "subgrains/nuclei" produced the appearance of an anomalous grain structure upon macro-etching. These inhomogeneities did not meet the product specifications. By identifying the source of these undesired inhomogeneities, a strong case was made to lower the final strain $<1$ in vendor A's forging through die design and/or the number of forging stages. These changes subsequently resulted in the production of a qualified forging by vendor $\mathrm{A}$.

\section{CONCLUDING REMARKS}

A clear picture of a deformed microstructure must include a number of elements to provide a solid basis for microstructure property relationships. These elements include the initial grain structure and orientation, presence or absence of macro-scale bands (e.g., deformation, transition or matrix bands) and cell blocks. The cell block is the basic unit that can be used to describe the full range of features in deformed metals and alloys of medium to high SFE. Slip pattern differences on both a large scale and on a cell block to cell block basis are recorded by the cell block. This legacy can be measured in the TEM by the cell block morphology, the magnitude of the misorientation angle/axis pair and the spacing of the extended GNBs defining a cell block, as well as by the cells and crystal orientations within the cell block. Both average quantities and distributions are required for a complete description. Selected examples have shown that these different cell block structures significantly affect the subsequent nucleation and growth of recrystallization.

\section{ACKNOWLEDGEMENTS}

The author would like to thank N. Hansen and A. Godfrey for their helpful discussions. This work was supported in part by the U.S. DOE Office of Basic Energy Sciences, Division of Materials Sciences under contract no. DE-AC04-94AL85000.

\section{REFERENCES}

Akef, A. and Driver, J. H. (1991). Orientation Splitting of Cube Oriented fcc Crystals in Plane Strain Compression. Mater. Sci. Engr. A132, 245-255.

Barlow, C. Y., Bay, B. and Hansen, N. (1985). A comparative investigation of surface relief structures and dislocation microstructures in cold-rolled aluminum. Phil. Mag. A. 1, 253275.

Barrett, C. S. and Levenson, L. H. (1940). The Structure of Aluminum after Compression. Trans. AIME. 137, 112-127.

Bay, B., Hansen, N., Hughes, D. A. and Kuhlmann-Wilsdorf, D. (1992). Evolution of fcc Deformation Structures in Polyslip. Acta metal. mater. 40, 205-219.

Bay, B., Hansen, N. and Kuhlmann-Wilsdorf, D. (1989). Deformation Structures in Lightly Rolled Pure Aluminum. Mater. Sci. Eng. A113, 385-397.

Becker, R., Butler, J. F. J., Hu, H. and Lalli, L. (1991). Analysis of an Aluminum Single Crystal with Unstable Initial Orientation (001) [110] in Channel Die Compression. Met. Trans. 22A, 45-58. 
Blicharski, M., Becker, R. and Hu, H. (1993). Acta metall. mater. 41, 2007.

Cahn, R. W. (1951). J. Inst. Metals. 79, 129.

Calnan, E. A. (1952). Acta Crystall. $5,557$.

Christoffersen, H. and Leffers, T. (1998). The orientation of dislocation walls in rolled copper relative to the sample coordinate system. Acta mater. 46, 4093-4102.

Dillamore, I. L. and Katoh, H. (1974). The Mechanisms of Recrystallization in Cubic Metals with Particular Reference to their Orientation Dependence. Metal Sci. 8, 73-83.

Doherty, R. D., Samajdar, I., Necker, C. T., Vatne, H. E. and Nes, E. (1995). In: Proceedings of the 16th Risø International Symposium: Microstructural and Crystallographic Aspects of Recrystallization(Edited by Hansen, N., Juul Jensen, D., Liu, Y. L. and Ralph, B. Risø National Laboratory, (Roskilde, Denmark), 1-24.

Driver, J. H. (1995). In: Proceedings of the 16th Risø International Symposium: Microstructural and Crystallographic Aspects of Recrystallization(Edited by Hansen, N., Juul Jensen, D., Liu, Y. L. and Ralph, B. Risø National Laboratory, (Roskilde, Denmark), 25-36.

Driver, J. H., Juul Jensen, D. and Hansen, N. (1994). Large Deformation Structures in Aluminum Crystals with Rolling Texture Orientations. Acta Metall. Mater. 42, 3105-3114.

Ferry, M. and Humphreys, F. J. (1995). In: Proceedings of the 16th Ris $\varnothing$ International Symposium: Microstructural and Crystallographic Aspects of Recrystallization(Edited by Hansen, N., Juul Jensen, D., Liu, Y. L. and Ralph, B. Risø National Laboratory, (Roskilde, Denmark), 359-364.

Fujita, H., Toyoda, K., Mori, T., Tabata, T., Ono, T. and Takeda, T. (1983). Dislocation Behavior in the Vicinity of Grain Boundaries in FCC Metals. Trans. Jap. Inst. Metals. 24, 195-204.

Ganapathi, S. K., Aindow, M., Fraser, H. L. and Rigney, D. A. (1991). A comparative study of the nanocrystalline material produce by sliding wear and inert gas condensation. Mat. Res. Soc. Symp. Proc. 206, 593-598.

Godfrey, A. and Hughes, D. A. (2000a). Recrystallization of layered microstructures developed in deformed single and bicrystals. to be submitted. .

Godfrey, A. and Hughes, D. A. (2000b). Scaling of the spacing of deformation induced boundaries. Acta mater. 48, 1897-1905.

Godfrey, A., Juul Jensen, D. and Hansen, N. (1995). In: Proceedings of the 16th Risø International Symposium: Microstructural and Crystallographic Aspects of Recrystallization(Edited by Hansen, N., Juul Jensen, D., Liu, Y. L. and Ralph, B. Risø National Labboratory, (Roskilde, Denmark), 365-370.

Godfrey, A., Juul Jensen, D. and Hansen, N. (1998a). Slip Pattern, Microstructure and Local Crystallography in an Aluminum Single Crystal of Brass Orientation $\{110\}<112>$. Acta. mater. 46, 823-833.

Godfrey, A., Juul Jensen, D. and Hansen, N. (1998b). Slip Pattern, Microstructure and Local Crystallography in an Aluminum Single Crystal of Copper Orientation $\{112\}<111\rangle$. Acta. mater. $46,835-848$.

Godfrey, A., Juul Jensen, D. and Hansen, N. (2000). Recrystallization of channel die deformed crystals of typical rolling orientations. submitted for publication.

Gottler, E. (1973). Versetzungsstruktur und Verfestigung von [100]-Kupfereinkristallen I. Versetzungsanordnung und Zellstruktur zugverformter Kristalle. Phil. Mag. 28, 1057-1076.

Hansen, N. (1985). Polycrystalline Strengthening. Metall. Trans. 16A, 2167-2190.

Hansen, N. and Hughes, D. A. (1995). Analysis of Large Dislocation Populations in Deformed Metals. Phys. Stat. Sol. (b). 149, 155-172.

Honeycombe, R. W. K. (1951). J. Inst. Metals. $\underline{80}, 49$.

Huang; X. and Hansen, N. (1997). Grain orientation dependence of microstructure in aluminum deformed by tension. Scripta Mater. 37, 1-7.

Huang, Y. and Humphreys, F. J. (2000). Subgrain growth and low angle boundary mobility in aluminum crystals of orientation. $\{110\}<001>$. Acta mater. $\underline{48}, 2017-2030$. 
Huang, Y., Humphreys, F. J. and Ferry, M. (2000). The annealing behavior of deformed cubeoriented aluminum single crystals. Acta mater. $\underline{48}, 2543-2556$.

Hughes, D. A., Chrzan, D. C., Liu, Q. and Hansen, N. (1998). Scaling of Misorientation Angle Distributions. Phys. Rev. Lett. 81 , 4664-4667.

Hughes, D. A. and Godfrey, A. (1998). In: Plasticity '99 Constitutive Modeling of Inelastic Deformation and Phase Transformation(Edited by Khan, A. S. Neat Press, (Fulton, Maryland), 153-156.

Hughes, D. A. and Hansen, N. (1993). Microstructural Evolution in Nickel during Rolling to Large Strains. Metall. Trans. A. 24A, 2021-2037.

Hughes, D. A. and Hansen, N. (2000). Microstructure and strength of nickel at large strains. Acta mater. 48, 2985-3004.

Humphreys, J. (1997). A Unified Theory of Recovery, Recrystallization and Grain Growth of Cellular Microstructures - I. The Basic Model. Acta mater. 45, 4231-4240.

Juul Jensen, D. (1995). In: Proceedings of the 16th Risø International Symposium: Microstructural and Crystallographic Aspects of Recrystallization(Edited by Hansen, N., Juul Jensen, D., Liu, Y. L. and Ralph, B. Risø National Laboratory, (Roskilde, Denmark), 119-138.

Kawasaki, Y. (1979). Jap. J. Appl. Phys. 18, 1429-1438.

Kawasaki, Y. and Takeuchi, T. (1980). Cell structure in copper single crystals deformed in the [100] and [111] axes. Scripta Metall. $\underline{14}, 183-188$.

Kuhlmann-Wilsdorf, D. and Hansen, N. (1991). Geometrically Necessary, Incidental and Subgrain Boundaries. Scripta Metall. Mater. 25, 1557-1562.

Lee, C. S., Duggan, B. J. and Smallman, R. E. (1993). A Theory of Deformation Banding in Cold Rolling. Acta Metall. Mater. 41, 2265-2270.

Liu, Q. and Hansen, N. (1998). Macroscopic and microscopic subdivision of a cold-rolled aluminum single crystal of cubic orientation. Proc. Roy. Soc. Lond. 454, 2555-2591.

Liu, Y. L., Hu, H. and Hansen, N. (1995). Deformation and Recrystallization of a Channel Die Compressed Aluminum Bicrystal with a (112)[111]/(123)[412] Orientation. Acta. Metall. Mater. 43 , 2395-2405.

Malin, A., Huber, J. and Hatherly, M. (1981). The Microstructure of Rolled Copper Single Crystals. Z. Metallkde. 72, 310-317.

Malin, A. S. and Hatherly, M. (1979). Microstructure of Cold-Rolled Copper. Metal Sci. 13, 463-472.

Medlin, D. L. and Hughes, D. A. (2000). Structure of high angle deformation induced boundaries. to be submitted. .

Morii, K. and Nakayama, Y. (1981). Trans. Japan Instit. Metals. 22, 857.

Mughrabi, H., Ungar, T., Kienle, W. and Wilkens, M. (1986). Long-range internal stresses and asymmetric $\mathrm{X}$-ray line-broadening in tensile deformed [100]-oriented copper single crystals. Phil. Mag. 53, 793-813.

Pantleon, W. (1998). On the statistical origin of disorientations in dislocation structures. Acta mater. 46, 451-456.

Read, W. T. and Shockley, W. (1950). Phys. Rev. 78, 275.

Rosen, G. S., Juul Jensen, D., Hughes, D. A. and Hansen, N. (1995). Microstructure and Local Crystallography of Cold Rolled Aluminum. Acta Metall. Mater. 43, 2563-2579.

Steeds, J. W. (1966). Dislocation arrangement in copper single crystals as a function of strain. Proc. Roy. Soc. A. 292, 343-373.

Swann, P. R. (1963). In: Electron Microscopy and Strength of Crystals(Edited by Thomas, G. and Washburn, J. Interscience Publishers, (New York), 131-182.

Sztwiertnia, K. and Haessner, F. (1996). In: Eleventh International Conference on Textures of Materials(Edited by Chu, Y., Liang, Z., Peizi, L., Zhou, L. and Zuo, L. The Nonferrous Metals Society of China, (Beijing), 549-554.

Wagner, P., Engler, O. and Lucke, K. (1995). Acta mater. 43, 3799. 


\section{Hughes}

Wert, J. A., Liu, Q. and Hansen, N. (1997). Dislocation boundary formation in a cold-rolled cube-oriented Al single crystal. Acta mater. 45, 2565-2576.

Winther, G., Huang, X. and Hansen, N. (2000). Crystallographic and macroscopic orientation of planar dislocation boundaries - correlation with grain orientation. Acta mater. $\underline{48}, 2187-$ 2198.

Wonsiewicz, B. C. and Chin, G. Y. (1970). Inhomogeniety of Plastic Flow in Constrained Deformation. Metall. Trans. 1, 57-61. 